\title{
دور الوساطة المالية الحديثة في أزمة الرهن العقاري
}

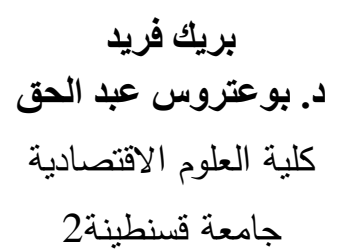

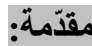

تشكل الوساطة المالية غير

المباشرة أهمية كبيرة

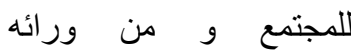

الاقتصاد ككل فمن خن خلال

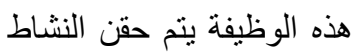

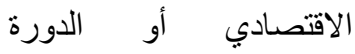

الاقتصادية بالسيولة اللازمة

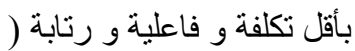

حجم و نوع السيولة اللازمة

) ) ، و ذلك انطلاقا من مبدأ

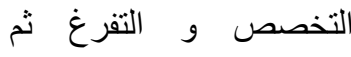

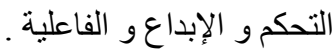

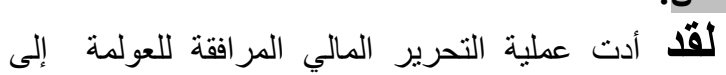

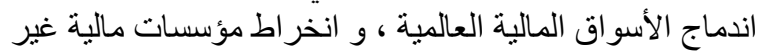

مصرفية في ممارسة نثاط الوساطة المالية المالية ، فتلاشىى مبداً

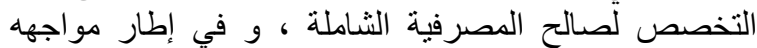

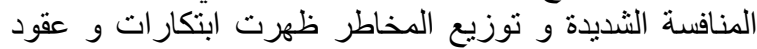

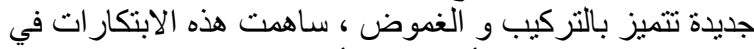

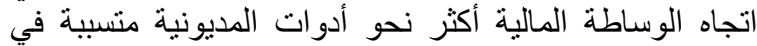

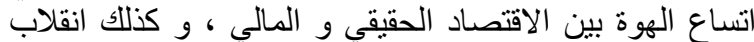

هرم السيولة العالمية ـ شكلت هذه الأوضاع تهائ العيدا للاستقرار

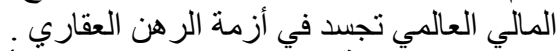

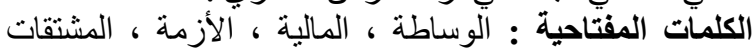

المالية ، التحرير المالي ، الأسواق المالية المالية الإلية

\section{Abstract:}

I have led the process of financial liberalization associated with globalization integration into global financial markets, and the involvement of financial institutions, non-banking practice brokerage, Vtlashy principle of specialization in favor of universal banking, and in the context of confronting intense competition and the distribution of risk appeared innovations and new contracts are characterized formulatorsand mystery, these innovations contributed to the direction of financial intermediation more towards debt instruments, causing the widening gap between the real economy and the financial, as well as the pyramid of global liquidity coup. These conditions formed a threat to the stability of the global financial embodied in the mortgage.

(C) جامعة الإخوة منتوري قسنطينة، الجزائر2016 
إن كفاءة وظيفة الوساطة المالية ليست في توظيف الادخار من خلال حقن السيولة كما ذكرنا فقط و إنما

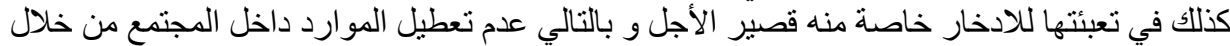

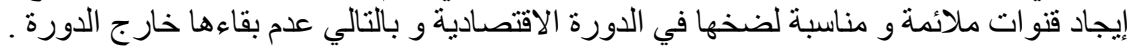

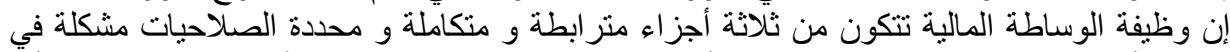

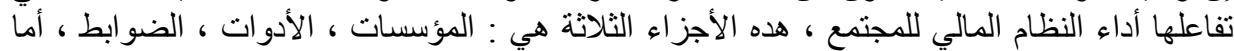

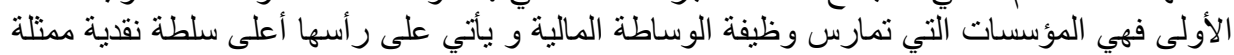

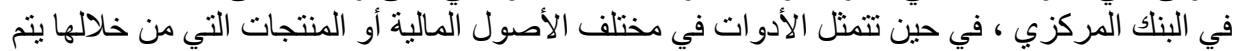

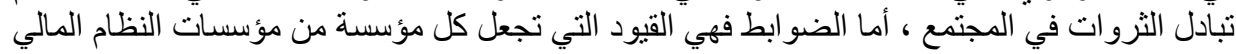

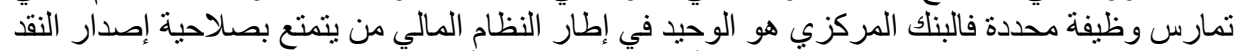

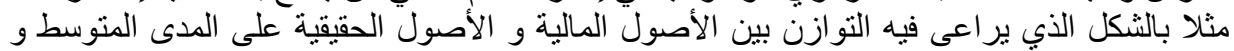

لقد أحدثت موجة التحرير المالي في نهاية القرن الماضي (بداية سنوات الثمانينات ) ثورة في مجال

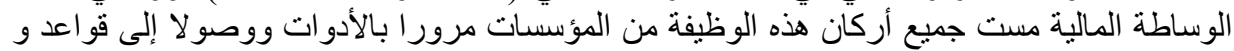

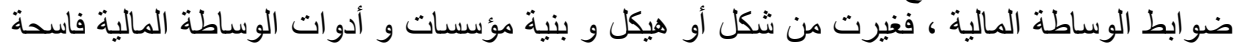

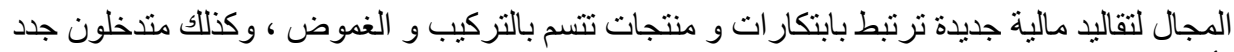

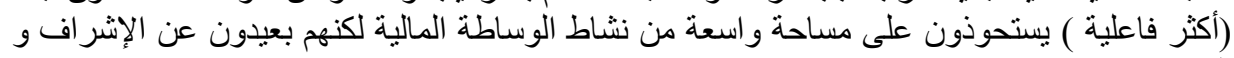

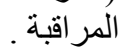

كما أن الأسواق المالية (أسواق الوساطة المالية) بدورها أصبحت تمارس أدوارا غير تقليدية تتجاوز

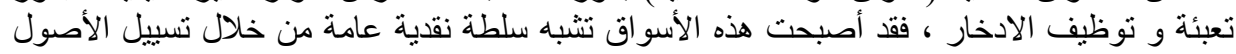

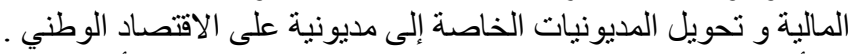

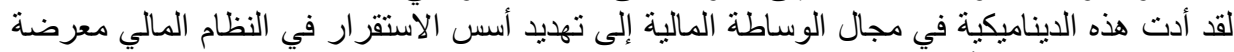

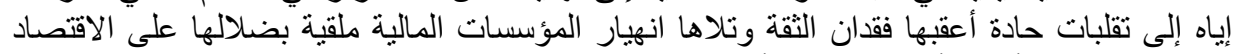

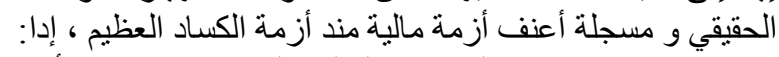

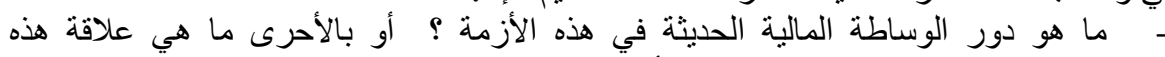

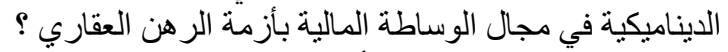
و للإجابة على هذا السؤال يمكن طرح الأسئلة الفرعية التالية التية :

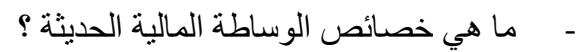

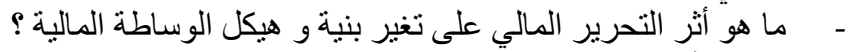
- - - ما هو أثر التغير في هيكل و بنية الوساطة المالية على الاستقرار المالي في أزمة الرهن

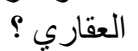
للإجابة على هذه الإثكالية قسمنا الموضو ع إلى ثلاث محاور كما يلي : -

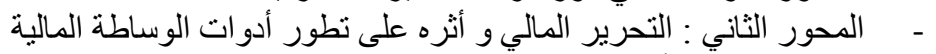
- المحور الثالث : أزمة الرهن العقاري ودور الوساطة المالية الحديثة 
المحور الأول : تزايد دور الوساطة المالية غير المصرفية و تغير هيكل الوساطة المالية

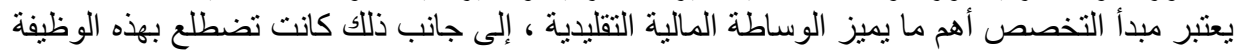

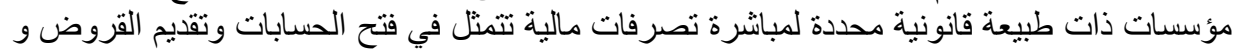

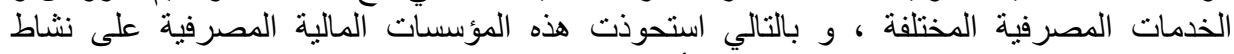

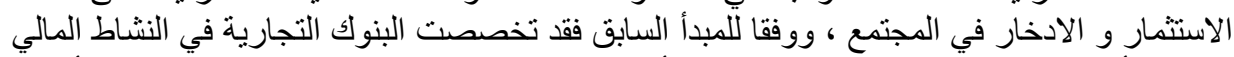

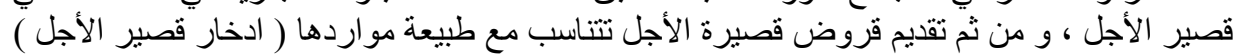

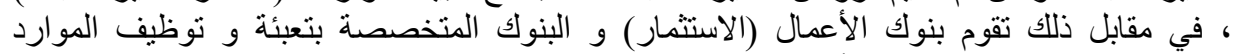

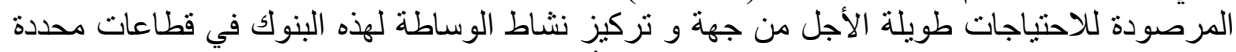

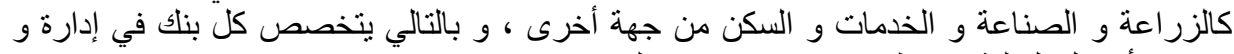

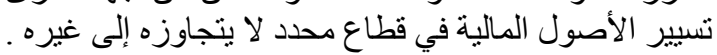

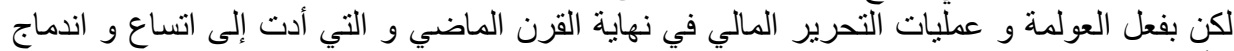

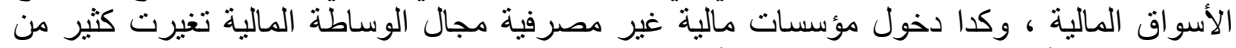

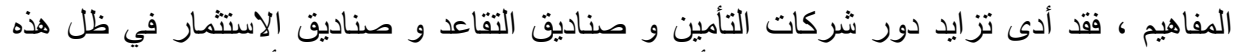

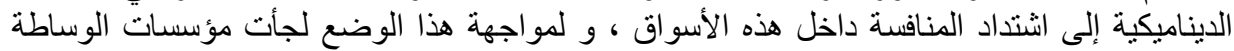

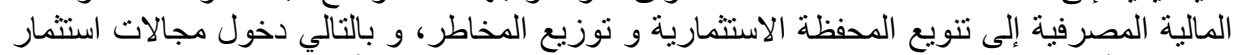

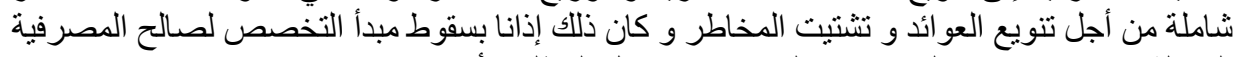

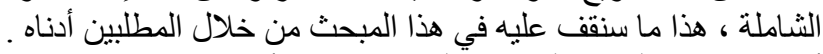

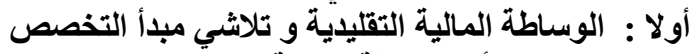
1-1 -1 مفهوم و نثأة الوساطة المالية المالية

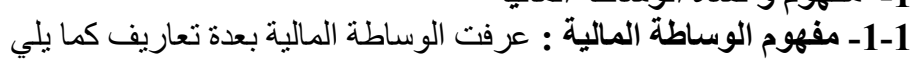

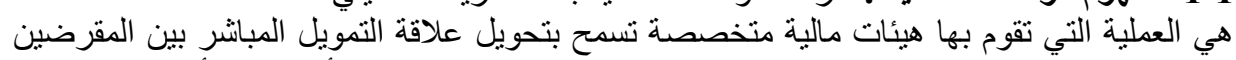

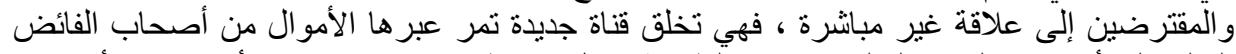

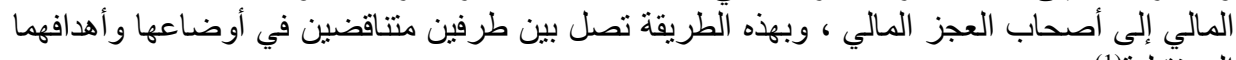

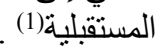

الوسطاء الماليون هم وحدات اقتصادية وظيفتها الأساسية شراء الأوراق المالية من المقترضين

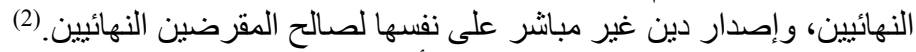

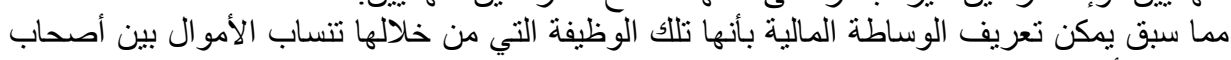

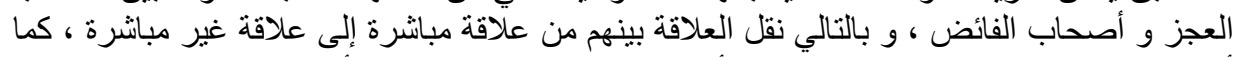

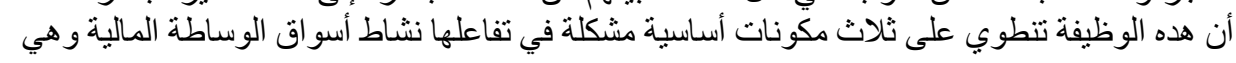

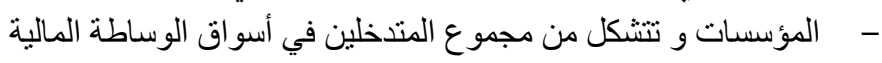

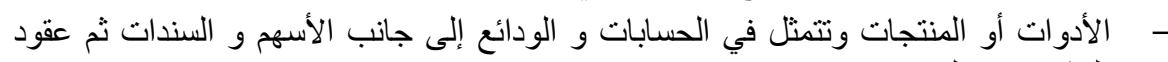
المشتقات و التو ريق النقات

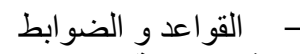

1- 2- نبذة تاريخية : كيف ظهرت و و تثكلت وظيفة الوساطة المالية

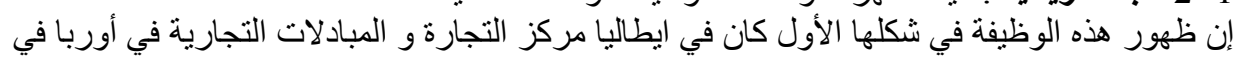

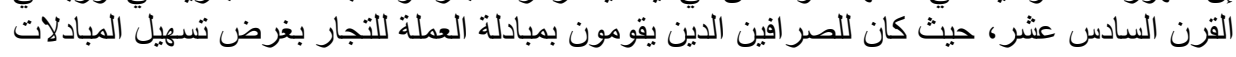

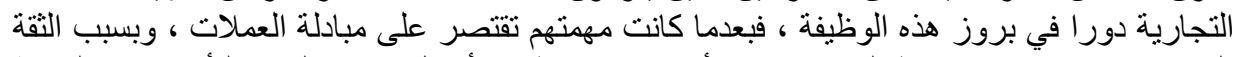

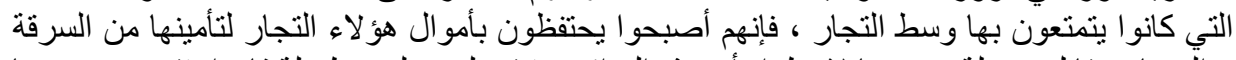

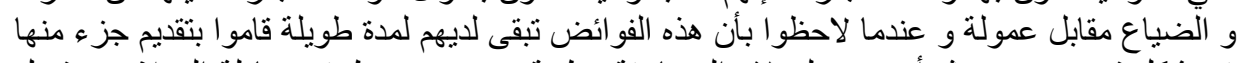

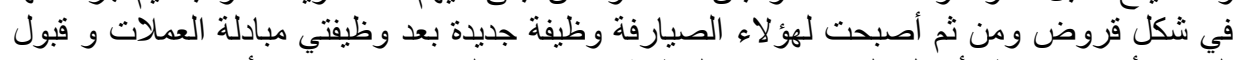

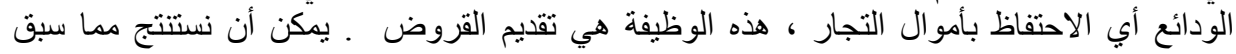

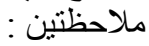




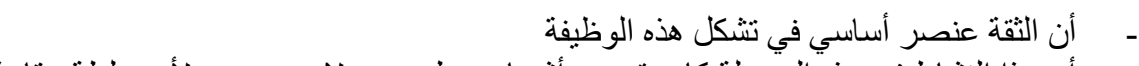

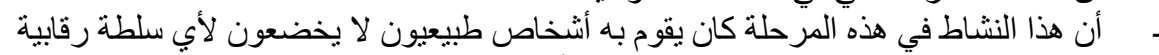

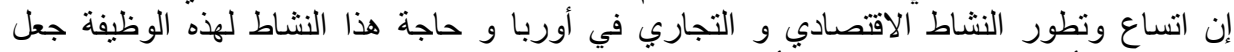

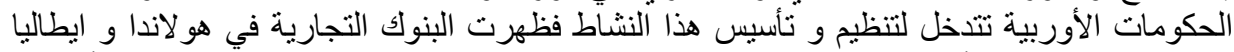

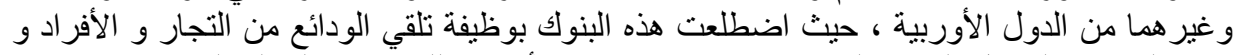

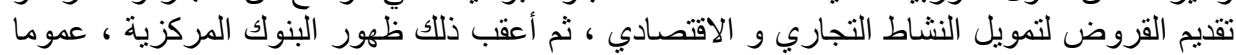

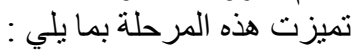

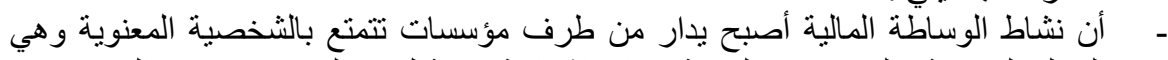

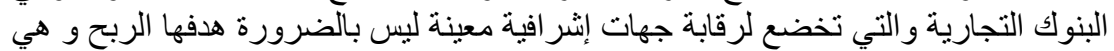

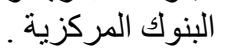

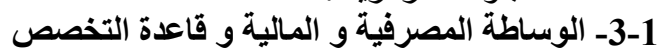

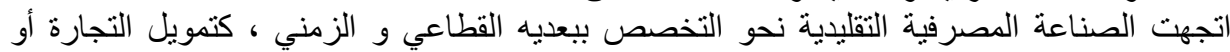

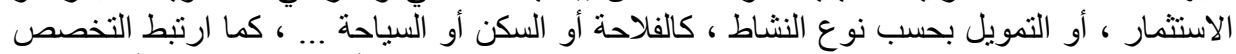

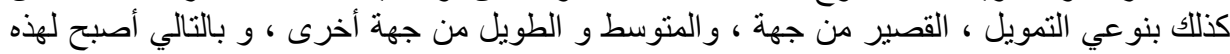

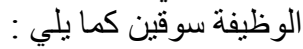
ـالسوق النقدي: هو عبارة عن سوق استثمار قصير الأجل لا يتجاوز تاريخ الاستحقاق فيه سنة واحدة

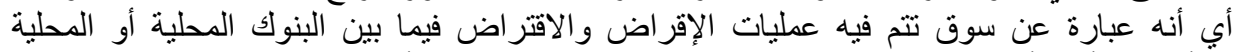

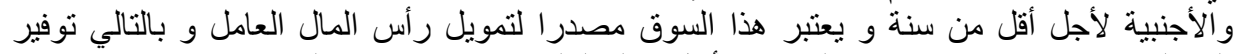

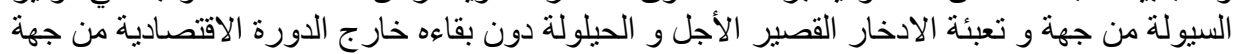

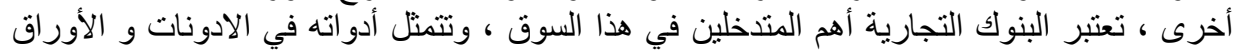

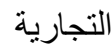

ـ سوق رأس المال : هو الذي يتم فيه تداول و تبادل الأدوات المالية طويلة الأجل و بالتالي هو عبارة

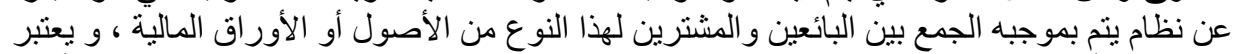

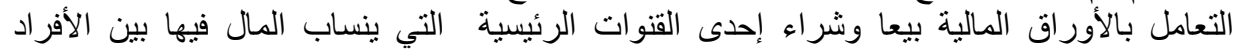

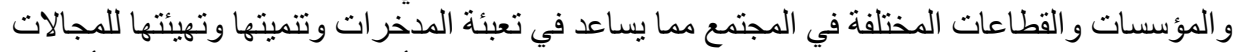

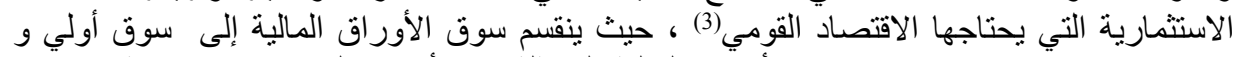

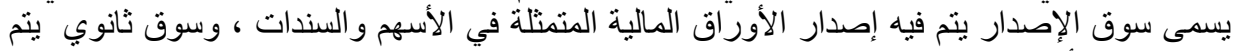

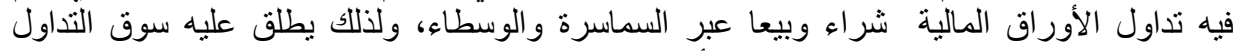

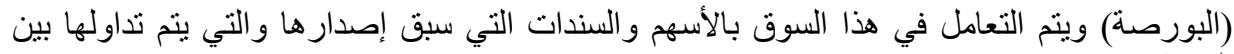

أما المندخلون في هذا السوق فهم بنوك الاستثمار (الأعمال) ، البنوك المتخصصة

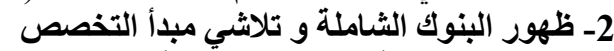

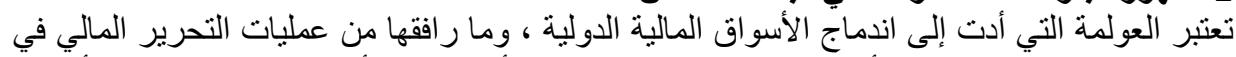

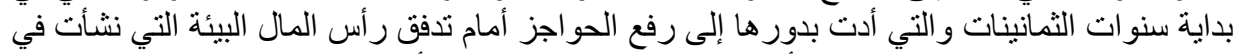

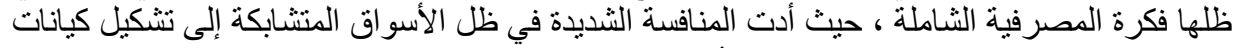

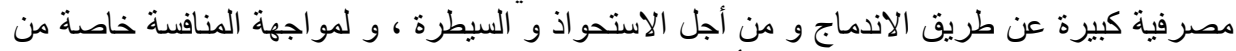

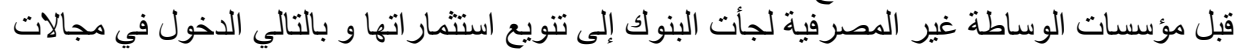

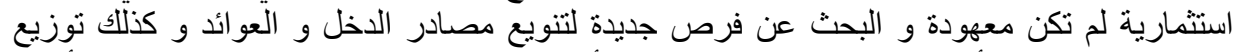

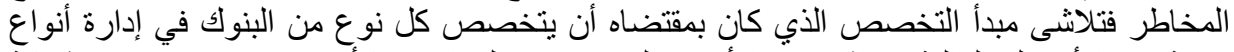

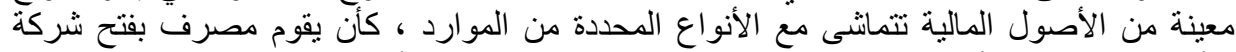

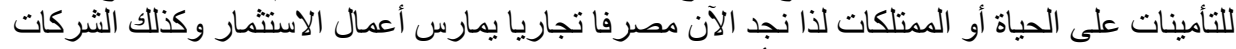

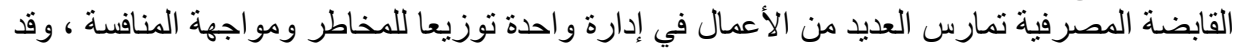


أضافت هذه المصارف إلى أعمالها المشتقات المالية والعقود المستقبلية وكافة الأدوات المستخدمة في الاستثمار و إدارة المخاطر المالية.

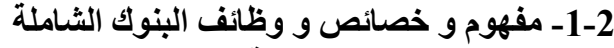

1-1-2

يمكن أن تعرف بأنها تلك الكيانات المصرفية التي تسعى دائما وراء تتويع مصاد التهادر التمويل وتعبئة

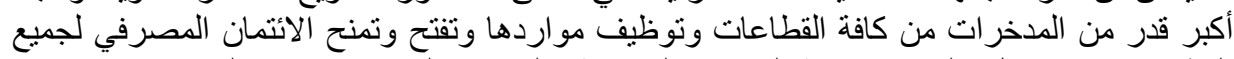

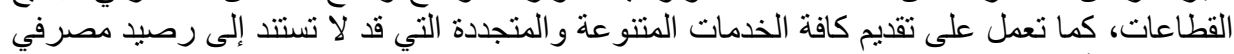

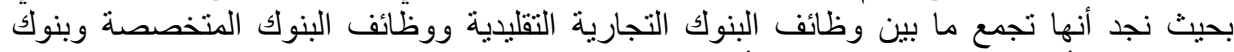

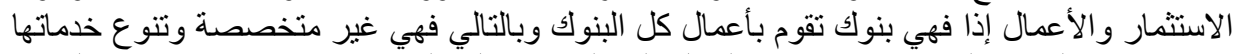

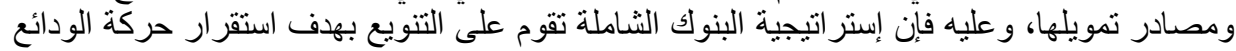

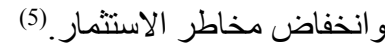

2-1-2

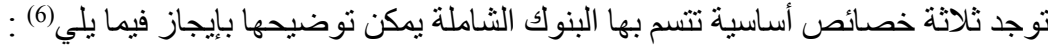

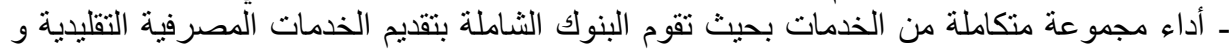

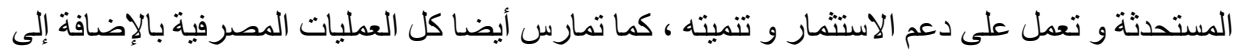

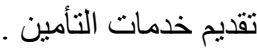

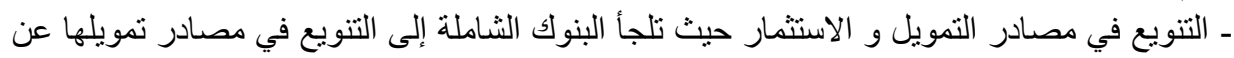

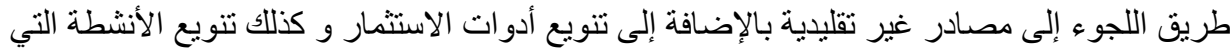

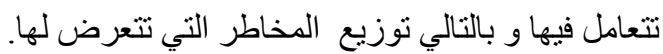
ـ الانتشار : حيث تمارس البنوك الثاملة أعمالها في مناطق جغر افية متعددة تنتشر فيها سو اء كان ذلك

داخل الدولة أو خارجها.

-3-1-2 - وظائف البنوك الثاملة

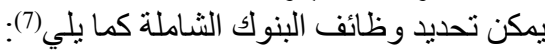

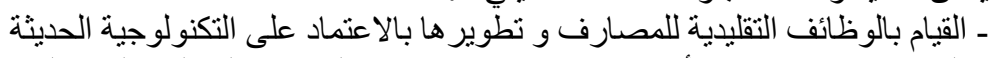

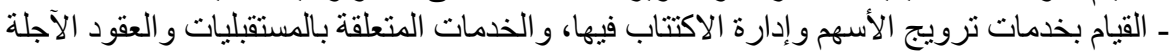

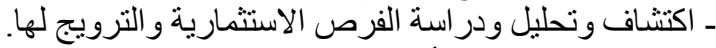

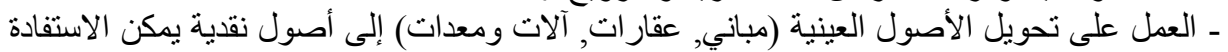
بها من قبل المساهمين و المستثمرين.

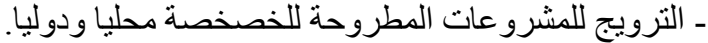

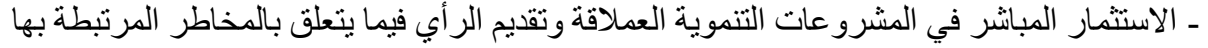

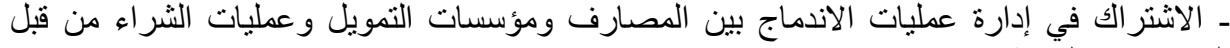

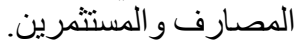

ثانيا: تزايد دور و أهمية الوساطة المبارينة المالية غير المصرفية

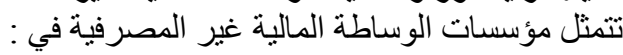

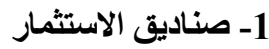
ظهرت سنة 1924 في و م الأمريكية ونمت بشكل كبير عقب الحرب العالمية الثانية حيث بلغ عددها

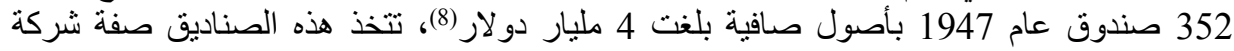

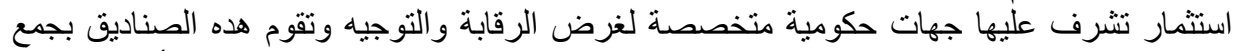

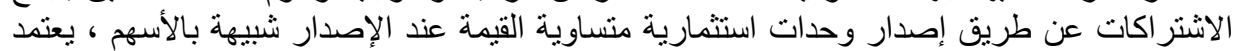

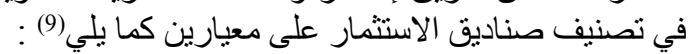


ـ هيكل رأس المال و بحسب هدا المعيار تتقسم صناديق الاستثمار إلى صناديق استثمار مفتوحة و صناديق استثمار مغلقة

- السياسة الاستثمارية و بحسب هدا المعيار نجد صناديق الأذون و الأوراق التجارية ، صناديق

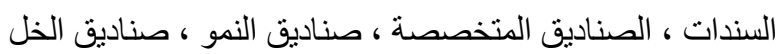

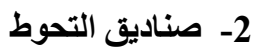

صندوق التحوط Fund Hedge وتدعى أيضاً المحفظة الوقائية هي صندوق استثمار بستخدم سياسات

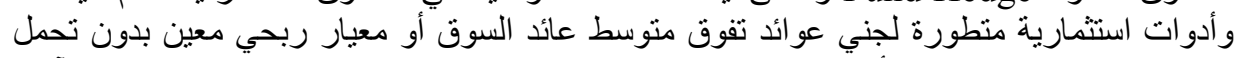

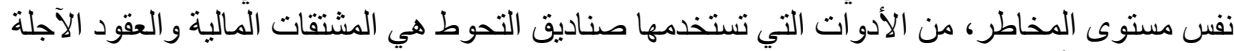

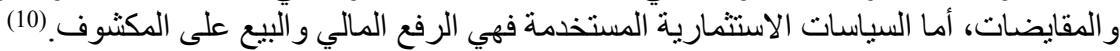

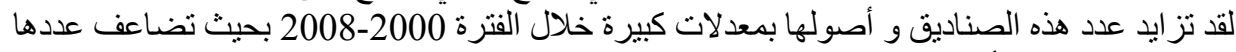
حو الي 12 مرة ، فأصبحت تسيطر على مساحة واسعة من نشاط الوساطة المالية ، و و الثكل المو الي

شكل 1 : تطور عدد صناديق التحوط من 2000-2008

\section{Estimated growth in commodity hedge funds}

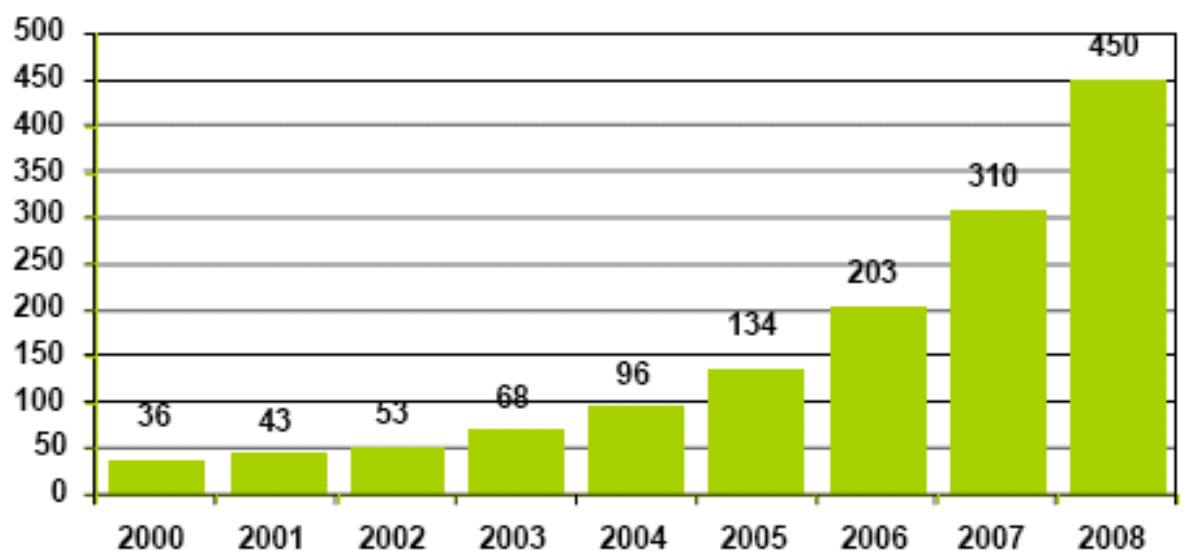

http://seekingalpha.com/article/77282-a-commodity-hedge-fund-in- المصدر every-pot\#comments_header

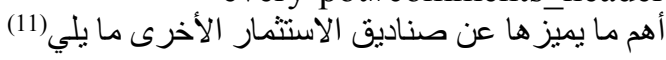

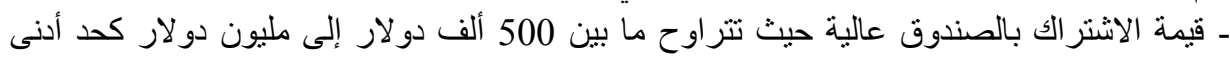

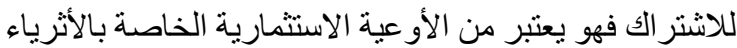

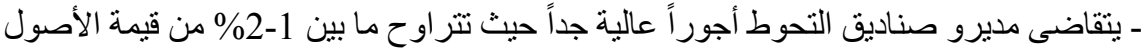

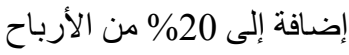

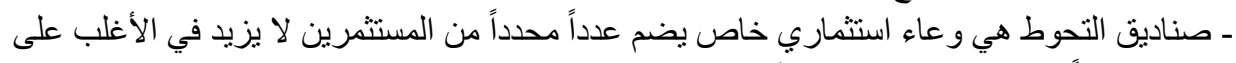
499 مستثمر أ غرضه الاستثمار في الأوراق المالية 
ـ صناديق التحوط غير خاضعة للتسجيل تحت أنظمة الجهات الرقابية المناط بها مراقبة الصناديق الاستثمارية لأنها عبارة عن عقد شركة بين المستثمر و الجهة المديرة للصندوق التهات

3- 3ن إديق التقاعد

هي مؤسسات مالية تقوم بجمع المساهمات من العاملين المستثمرين بالضمان وتكون مؤن مؤسسات خاصة

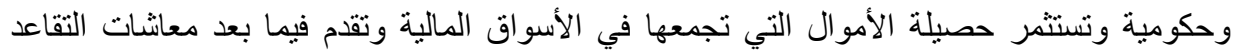

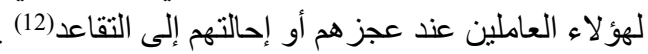

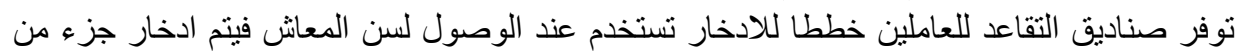

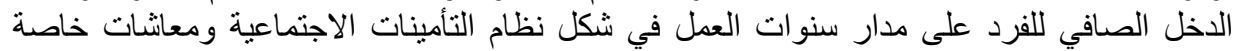

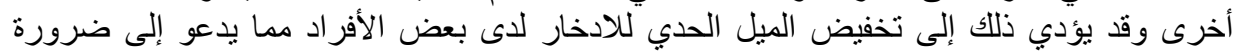

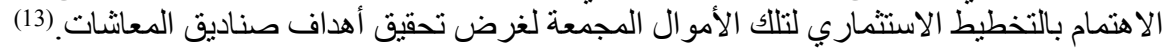

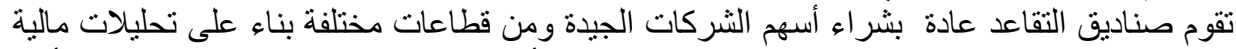

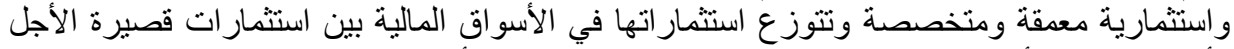

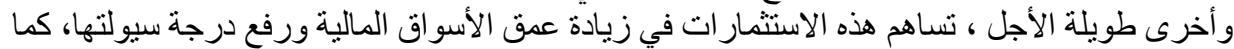

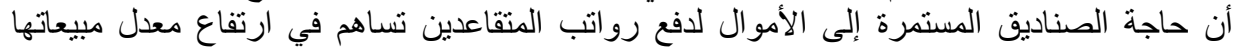

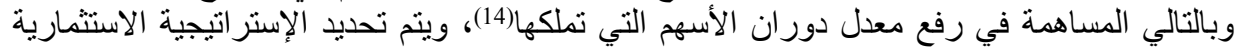

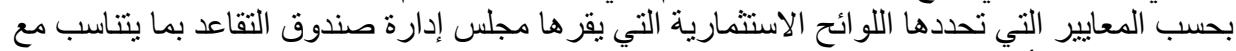

عمر الصندوق وأعداد المشتركين والمنتفعين فيه وحجم التزائن الماته المالية(15) .

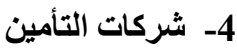

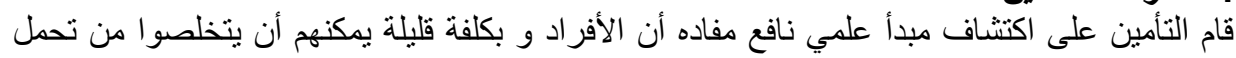

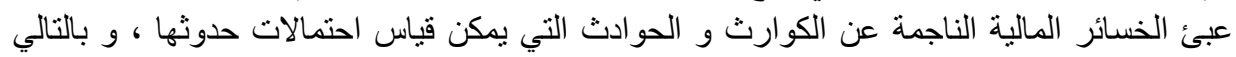

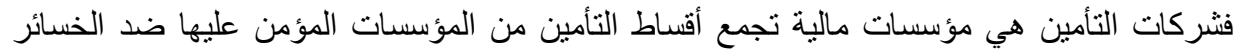

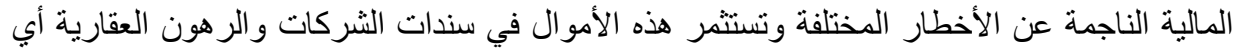

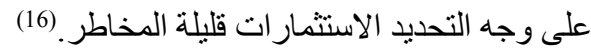

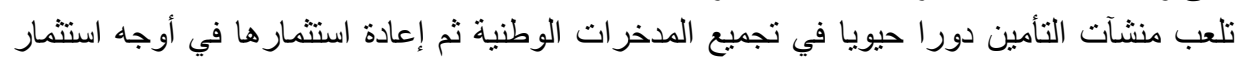

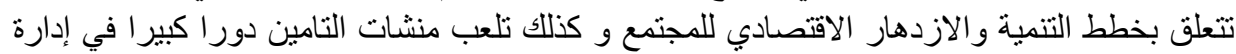

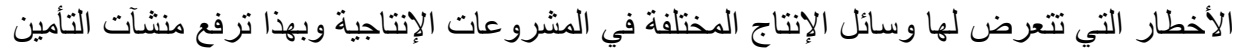

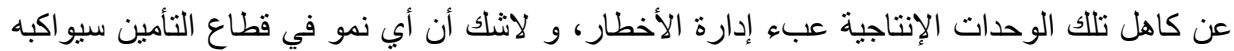

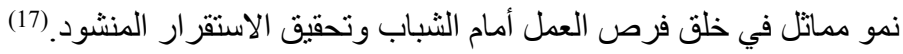

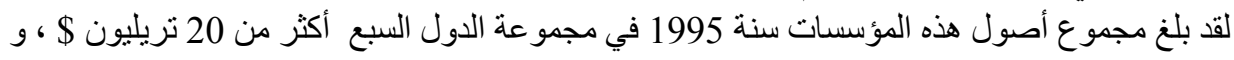

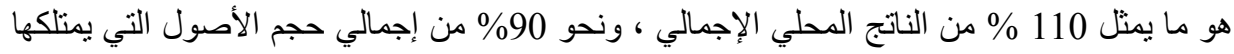

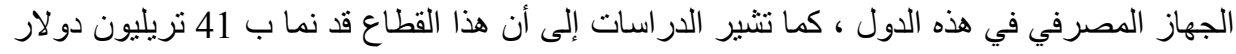

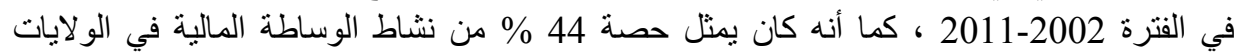

المتحدة سنة 2005 (18).

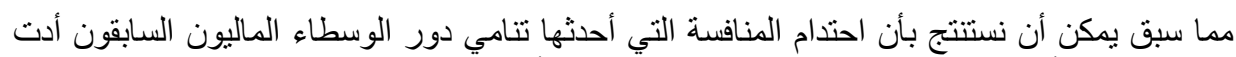

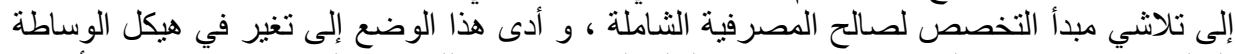

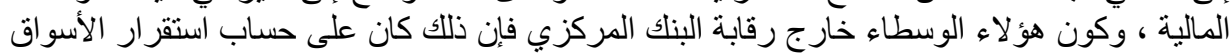

المحور الثاني : التحرير المالي و دوره في تطور أدوات الوساطة المالية 


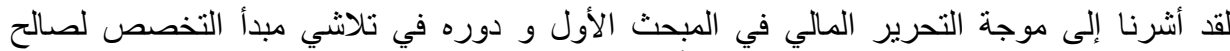

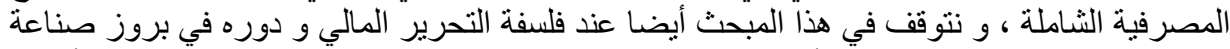

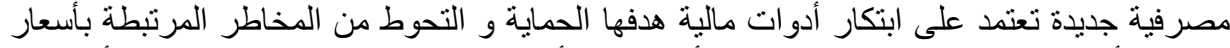

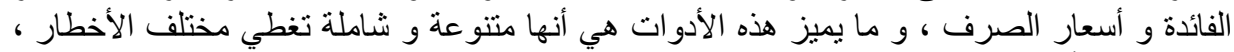

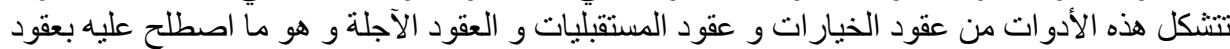

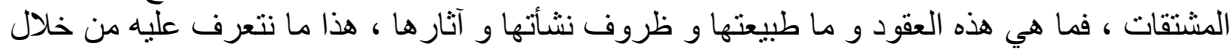
هذا المبحث

أولا : نشأة التحرير المالي و فلسفته 1- 1 ماهية و نشأة التحرير ألمالي التي

تعني عملية التحرير المالي رفع الحواجز المالمام المام حركة رأس المال التي تعبر عن تدفق الأرصدة المالية

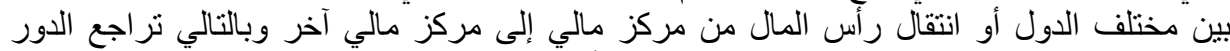

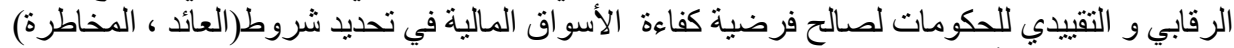

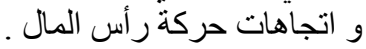

بدأت عملية التحرير المالي أوائل الثمانينيات في الولايات المتحدة الأمريكية ثم انتقلت إلى اليابان

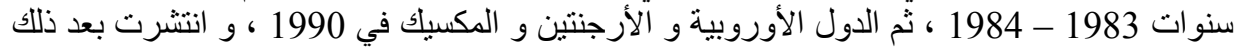

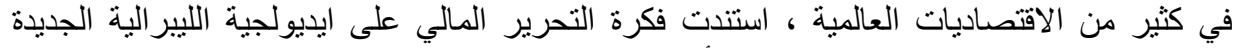

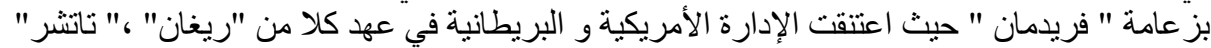

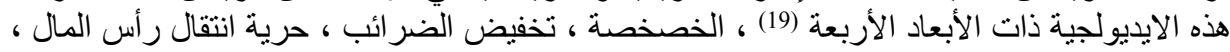

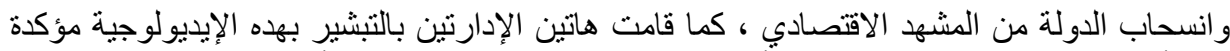

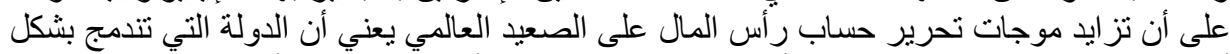

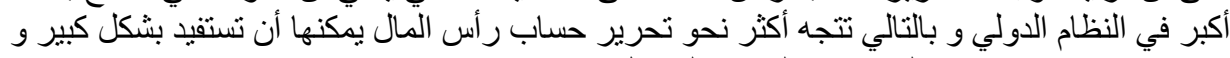

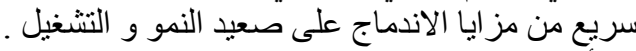

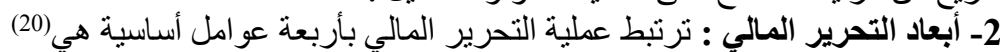

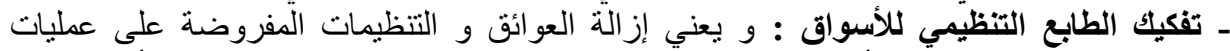

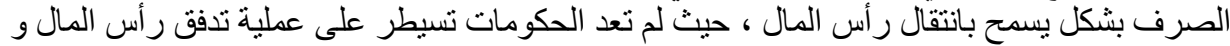

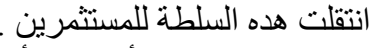

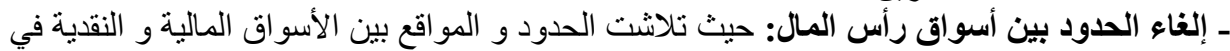

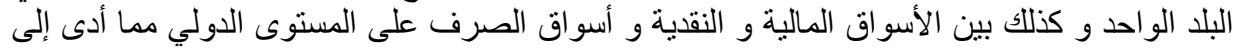

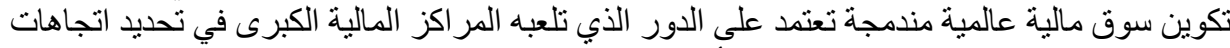

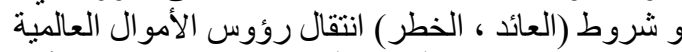

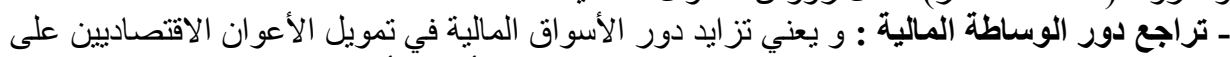

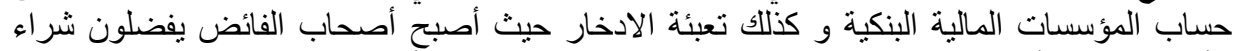

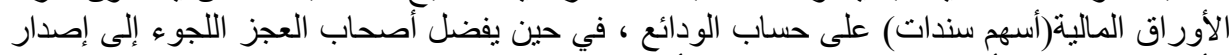

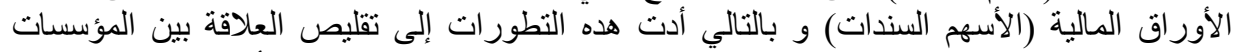

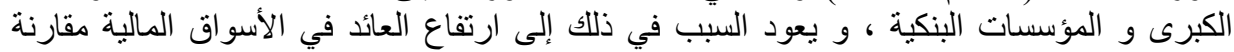

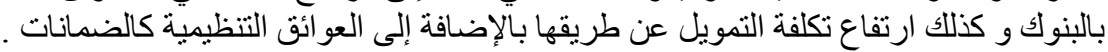

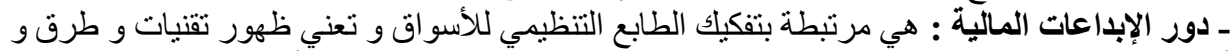

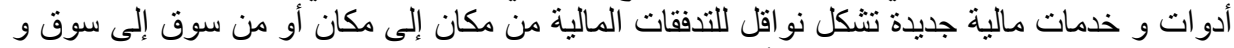

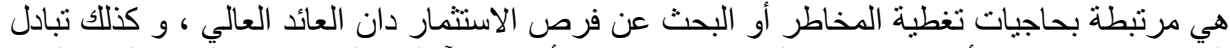

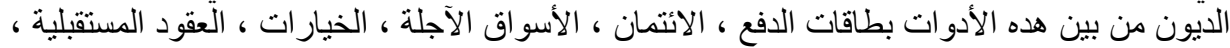

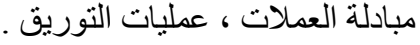


3- مزايا حركة رأس المال تمثل هذه المزايا الأسباب التي تدعو أو تبرر حركة انتقال رأس المال و

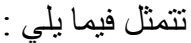
ـ تعتبر حركة رأس المال آلية تسمح باستعمال مخزون الادخار العالمي بثكل أفضل ، حيث يتدفق رأس

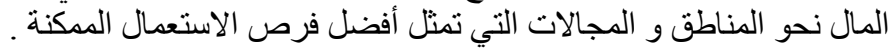

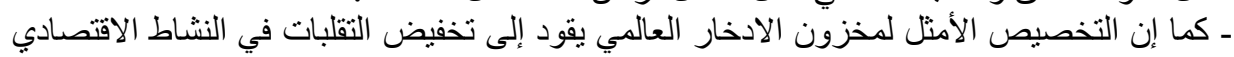

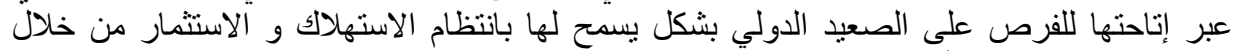

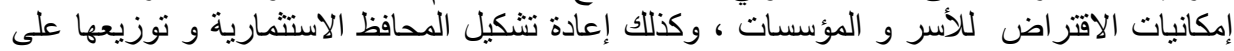

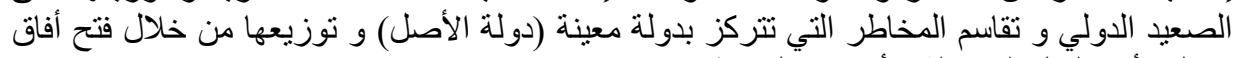

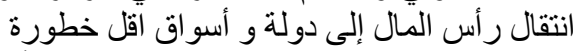

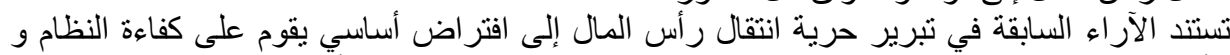

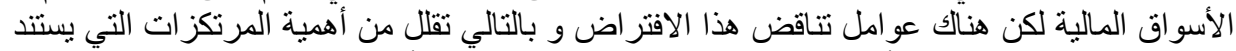

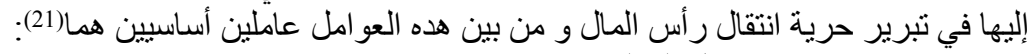

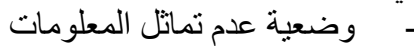

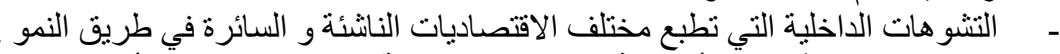

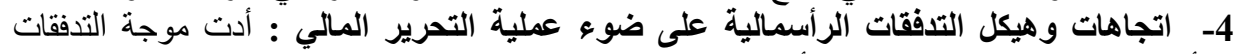

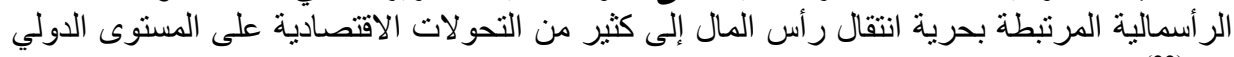
: (22) من

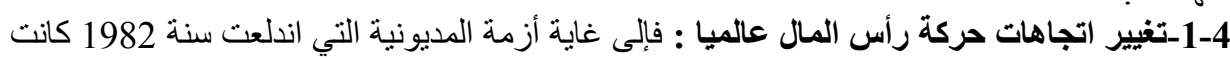

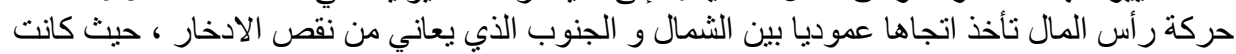

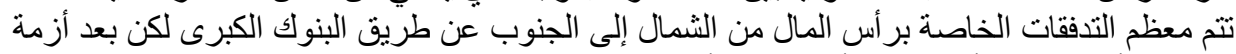

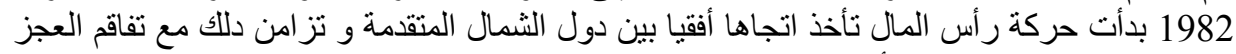

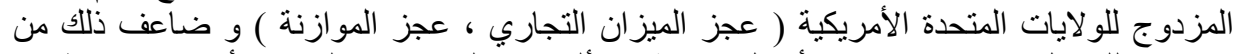

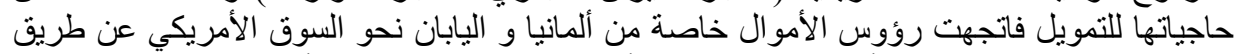

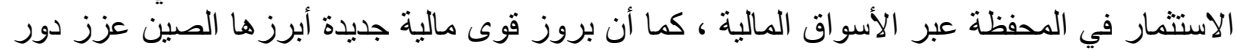
الدول النانشئة في الساحة المالية الدولية الئية

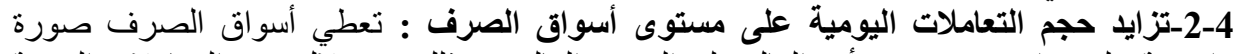

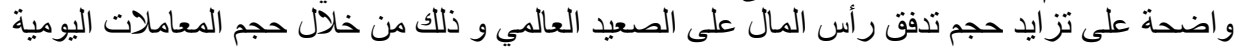

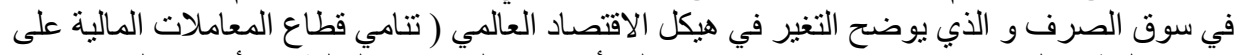

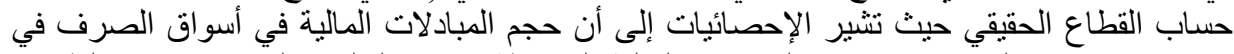

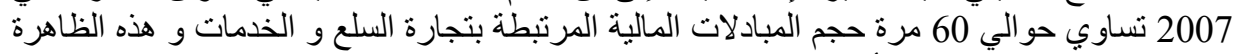
تعكس حجم المضاربات في الأسو اق المالية ) .

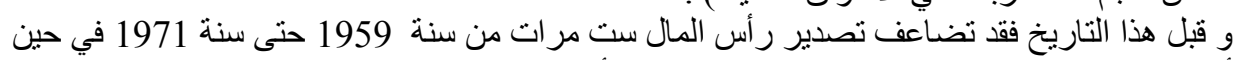

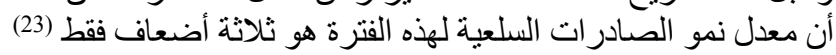

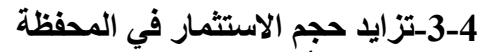
تتخذ حركة رأس المال على المستوى الدولي شكلين من الاستثمار هما الاستثمار المباثر و الاستثمار

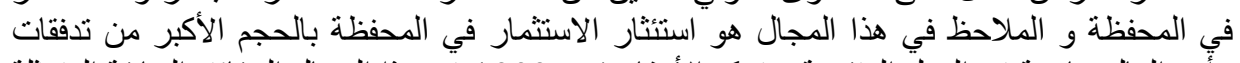

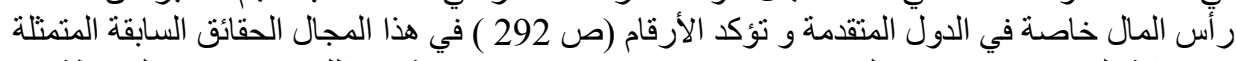

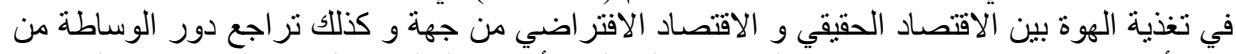

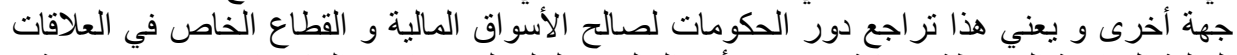

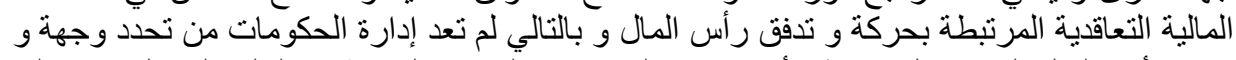

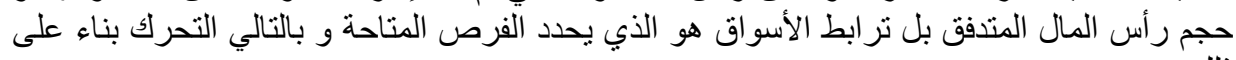


ثانيا : الابتكارات الجديدة و تطور أدوات الوساطة المالية

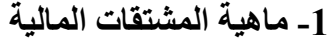

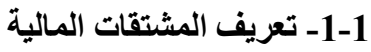

تعتبر المشتقات من العقود المستحدثة و تتسم بالتعقيد و التركيب وقد عرفت بعت بعدة تعار يف كما يلي :

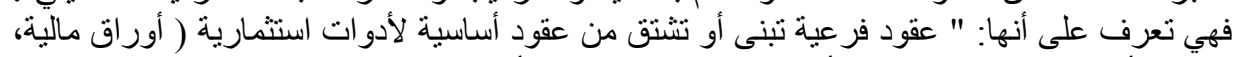

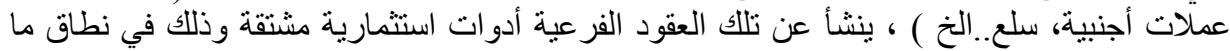
اصطلح عليه بالهندسة المالية "(24). وقد عرفها بنك التسويات الدولية على أنها " عقود تتوقف قيمتها على أسعار الأصول المالية محل التعاقد

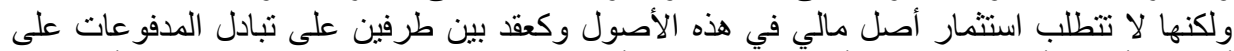

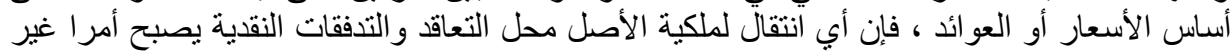

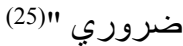

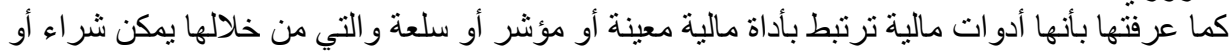

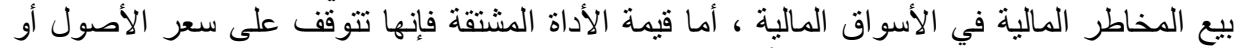

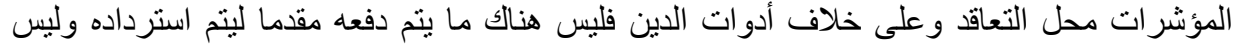

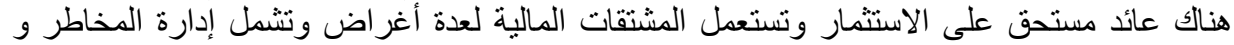

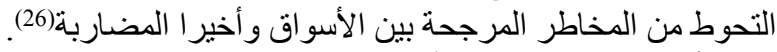

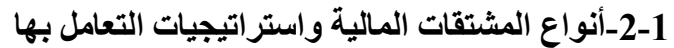

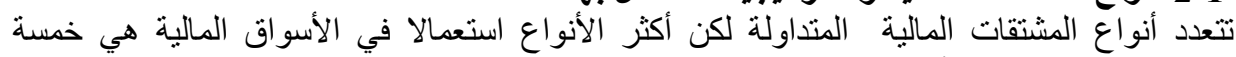

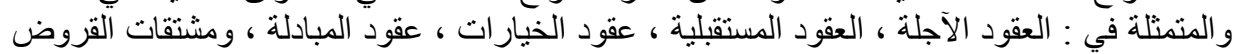

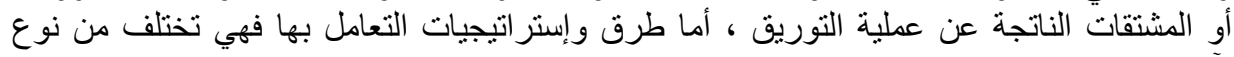
لآخر.

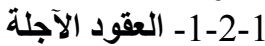

العقود الآجلة Forwards تعرف كذلاجك بالعقود الأساسية وهي نوع من أنواع الإع المشتقات المالية التي يتم

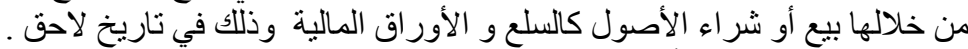

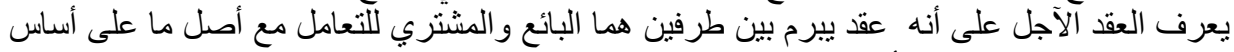

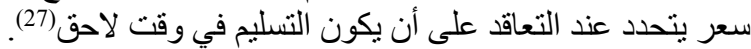

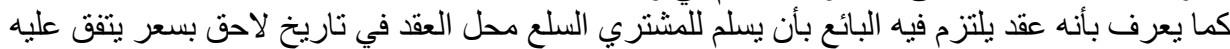
في وقت التعاقد يطلق عليه سعر التنفيذ(28).

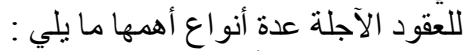

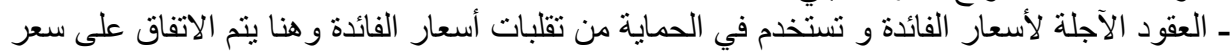

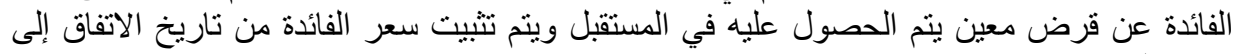

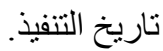
ـ العقود الآجلة لأسعار الصرف و هي اتفاق بين طرفين لثر اء أو بيع كمية معينة من عملة أجنبية مقابل

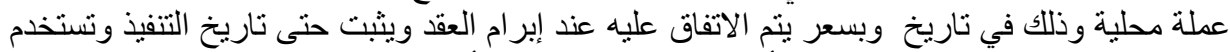
هذه العقود للحماية ضيد مخاطر تقلبات أسعار صرف العاف العملات الأجنبية. 2-2-1 - 2-2- العقود المستقبلية

العقد المستقبلي هو اتفاق بين طرفين على شراء الو أو بيع أصل ما في وقت معين في المستقبل بسعر

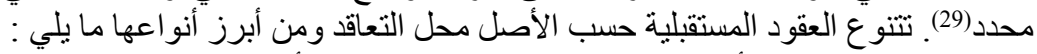

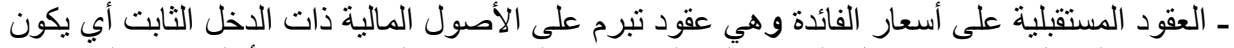

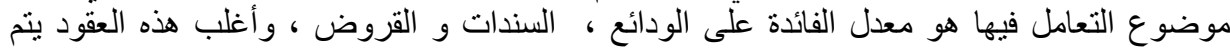
إحلالها قبل تاريخ الاستحقاق بصفة عكسية عن تللك التي تم الاتفاق عليها في البداية وضمن هذه العقود 
ـ عقود مستقلية على أوراق مالية لمعدلات فائدة قصيرة الأجل، مثل العقود المستقلية على الودائع

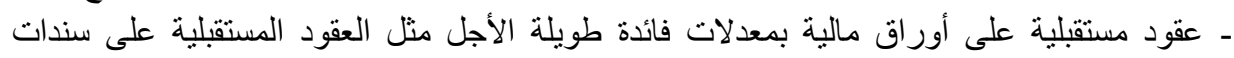
الخزينة

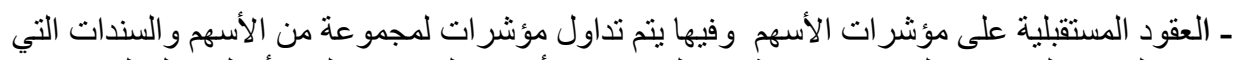

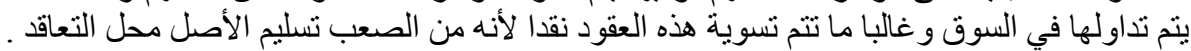

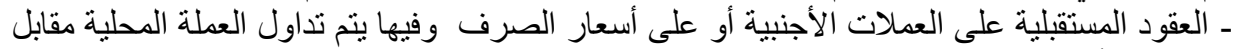
العملات الأجنبية. ـ العقود المستقبلية على السلع وهي عقود ينم إبر امها على سلع معينة كالبترول و القمح .

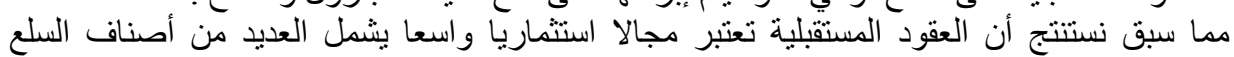
و الأدوات المالية وحتى الخدمات التئن

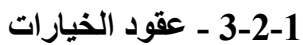

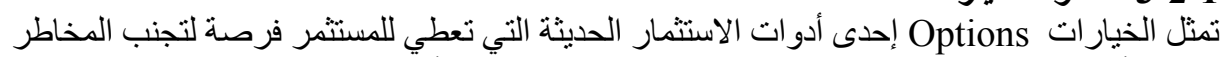

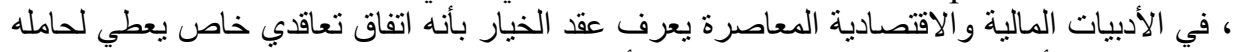

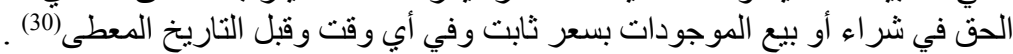

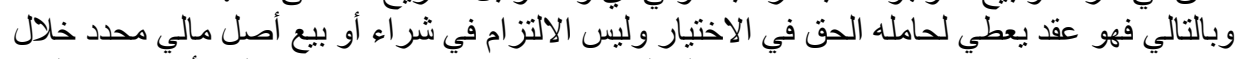

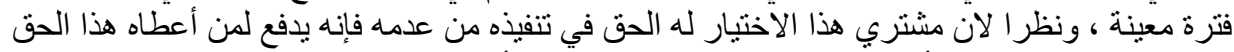

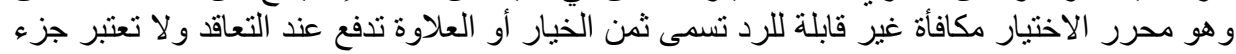

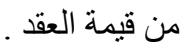

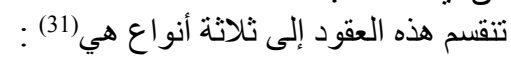

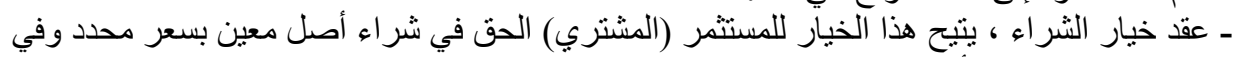

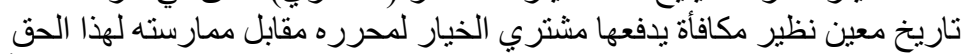

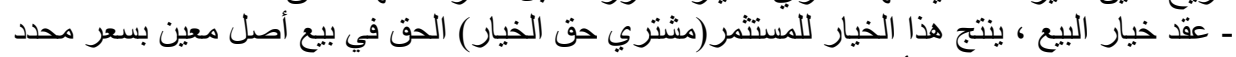

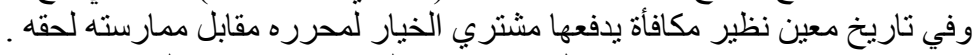

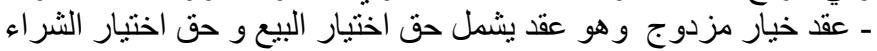

-3-1 - أهمية المشتقات المالية

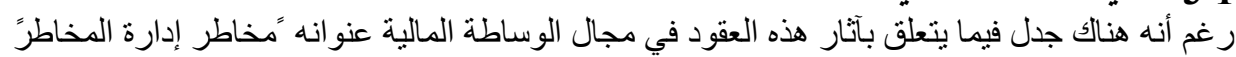

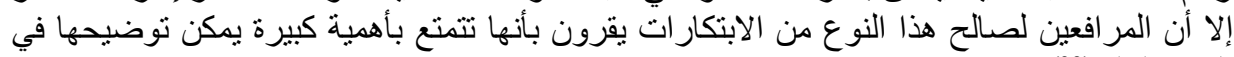

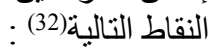

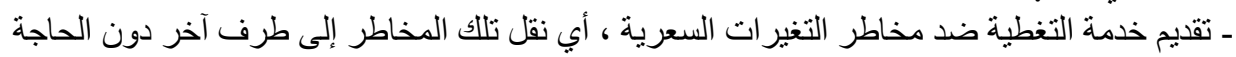

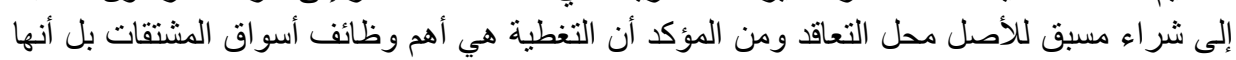

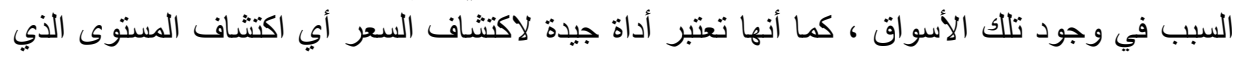

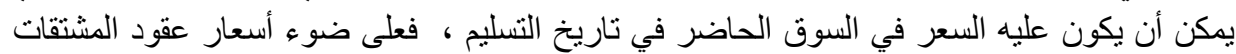

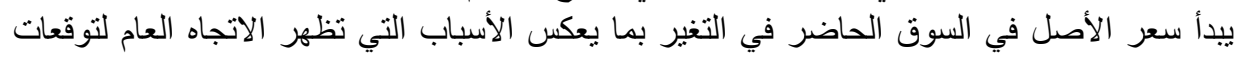

- إتاحة فرصة أفضل لتخطيط التدفقات النقدية بحيث تتيح عقود المشتقات الفرصة لتخطيط التدفقات

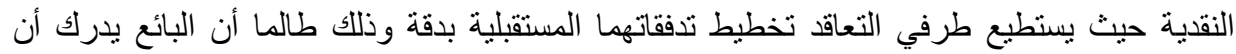

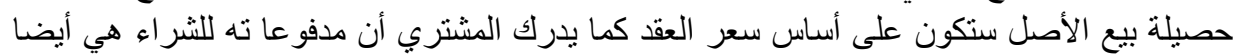
على أساس سعر العقد العاس

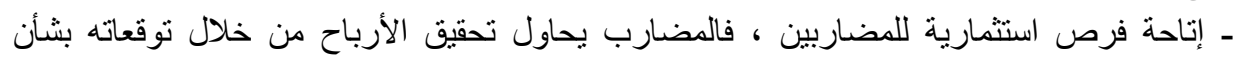

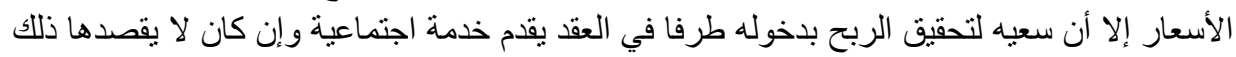




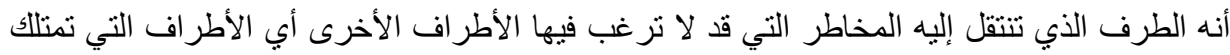

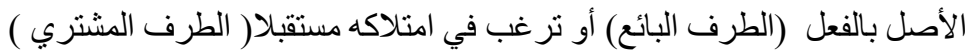

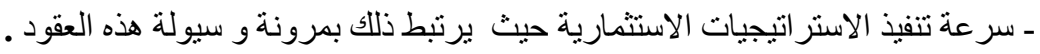

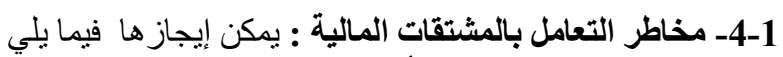

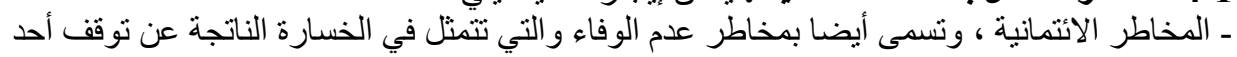

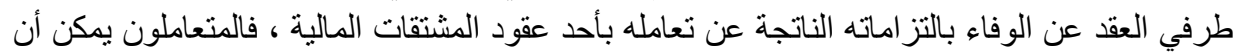

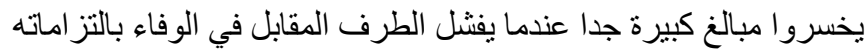

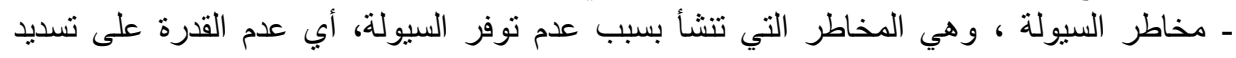
الالتزامات في تاريخها من قبل المتعاملين في سوق المشتقات مما يجعل المتاجرة بهذه الأدوات ألكات أكثر صعوبة

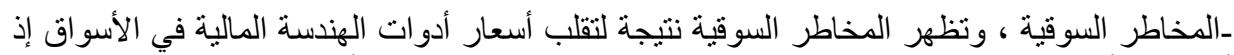

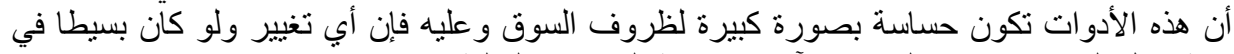

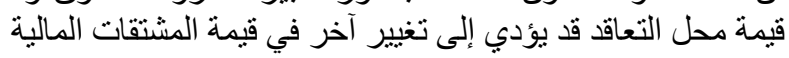

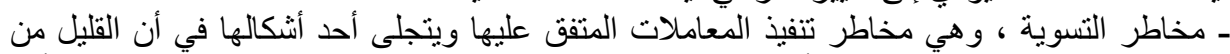

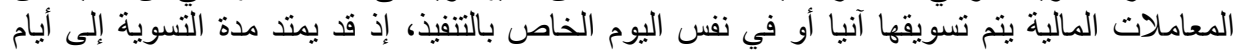

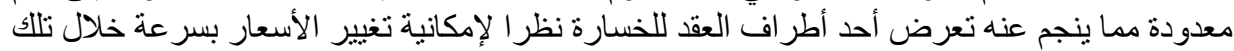
المدة و لاسيما في يوم التنفيذ ذاته.

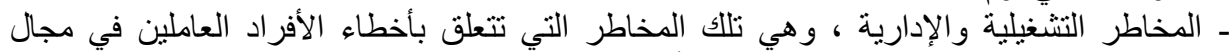

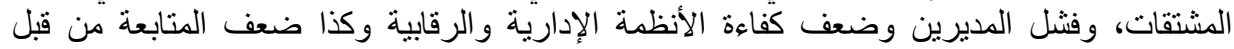

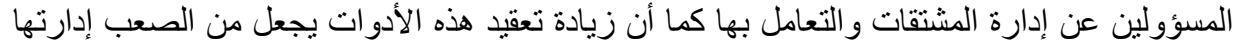

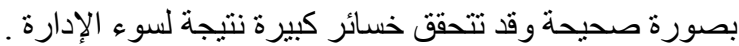

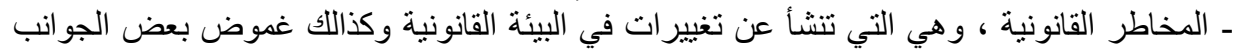

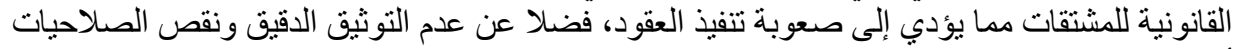

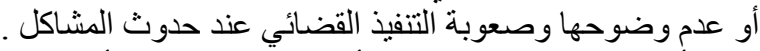

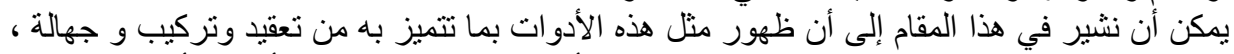

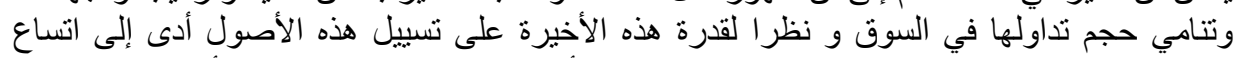

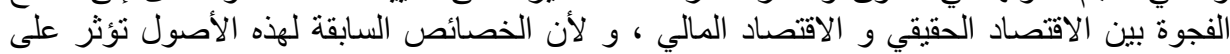
شفافية الأسواق المالية وكفاءتها فقد أدى ذلك إلى تقلبات حادة في أسعار الأصول المالية المبنية على هذه لألى

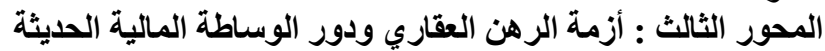

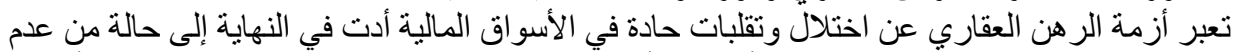

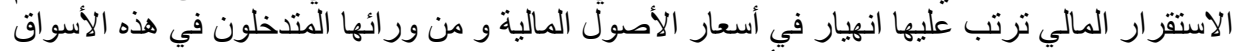

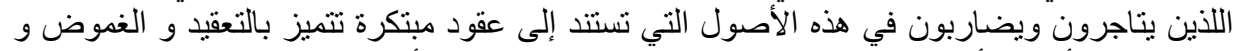

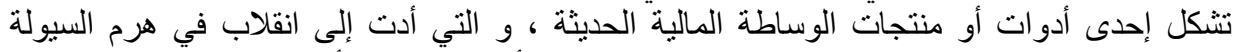

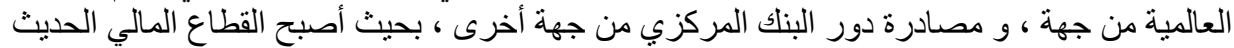

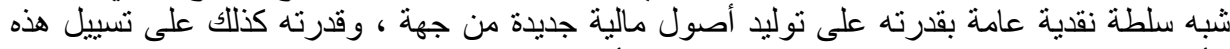

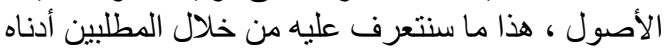

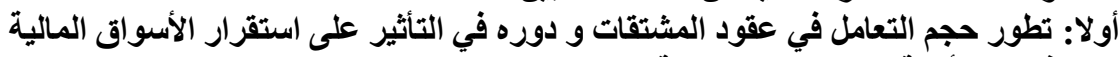

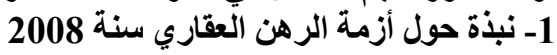

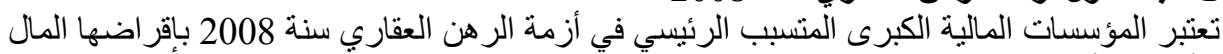

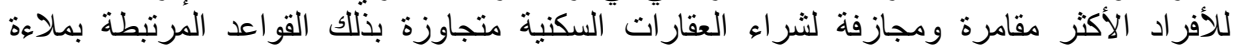


المقترضين و وقدرتهم على الوفاء و بالتالي منح القروض للأشخاص القادرين على إعادتها

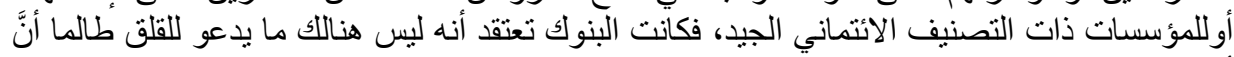

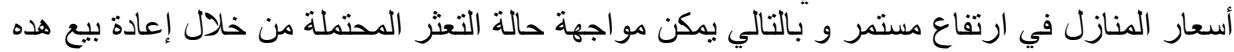

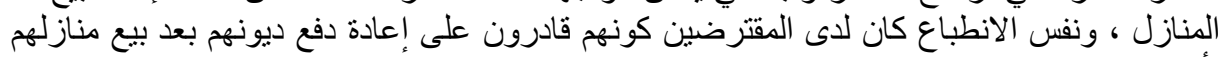

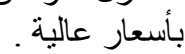

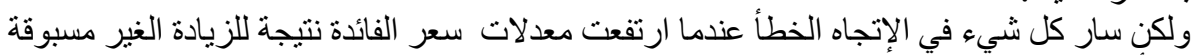

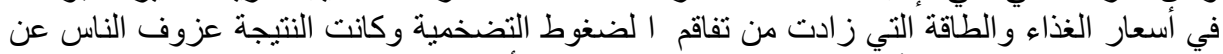

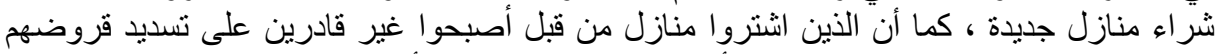

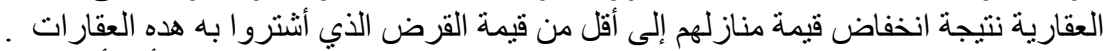

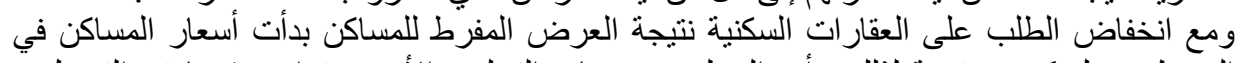

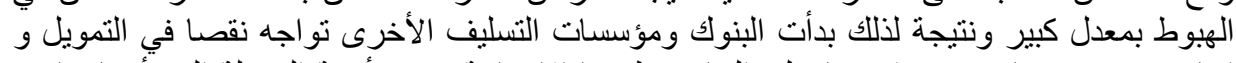

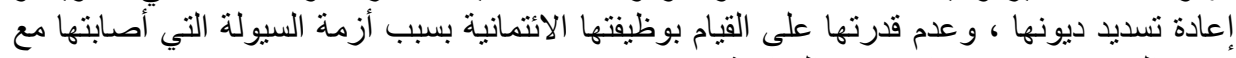

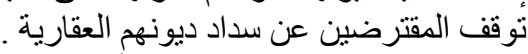

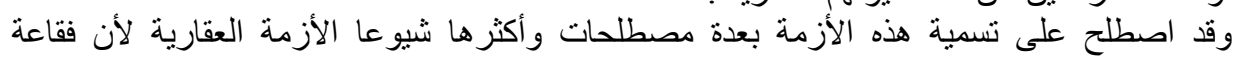

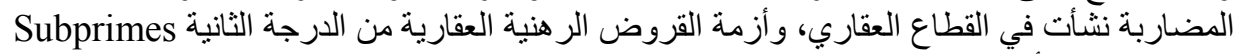

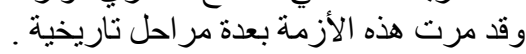

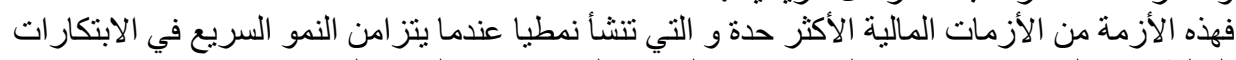

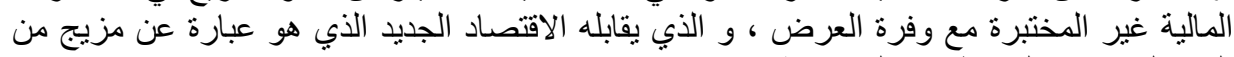

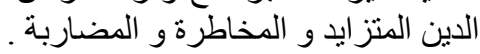

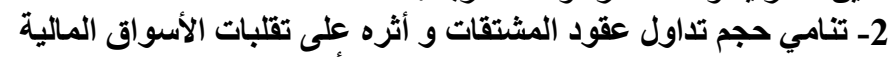

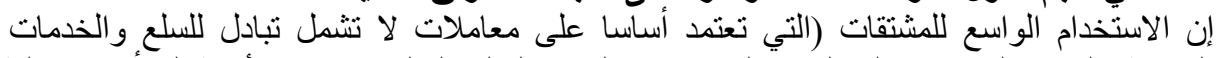

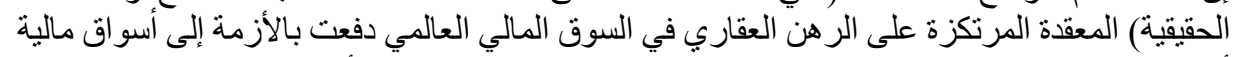

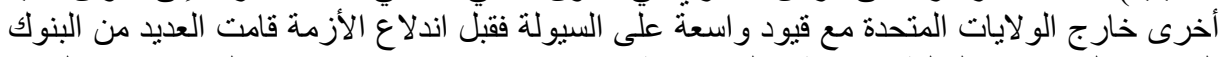

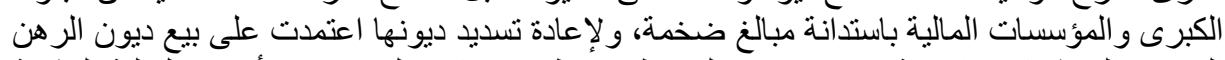

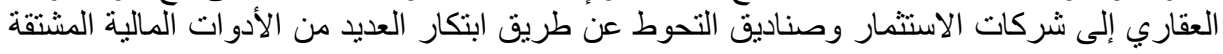

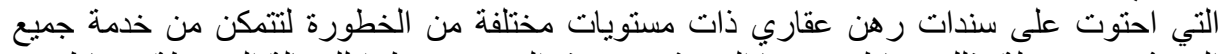

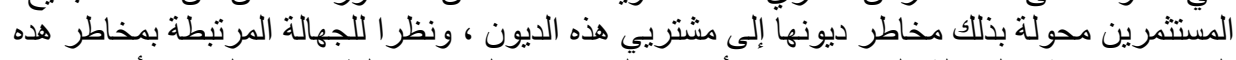

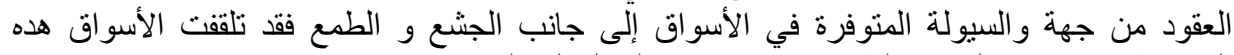

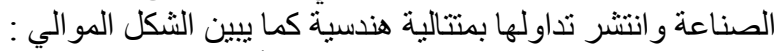

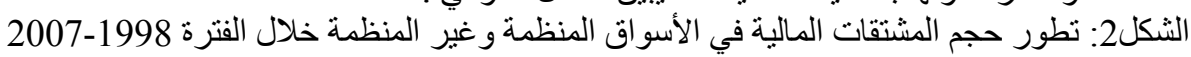
( الوحدة مليار دولار) 


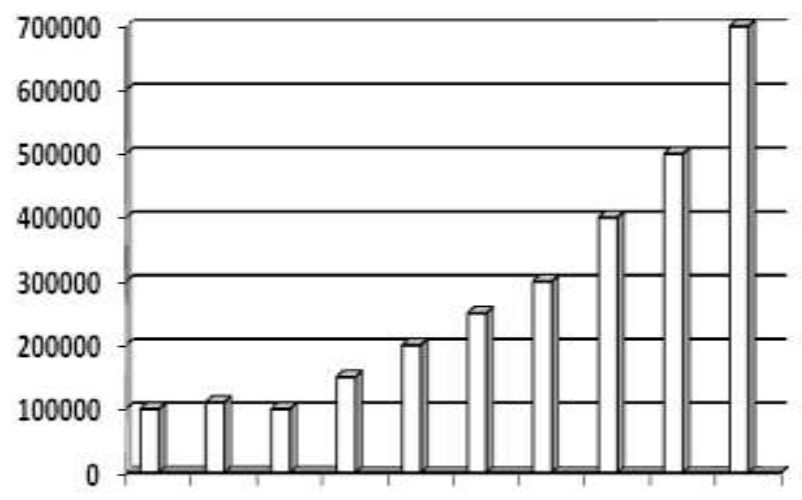

QExchange traded contracts

口OTC Derivatives

1998199920002001200220032004200520062007

المصدر : إحصائيات بنك النسويات الدولية

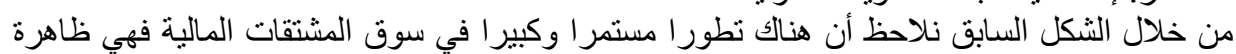

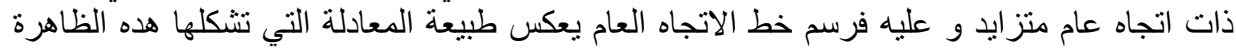

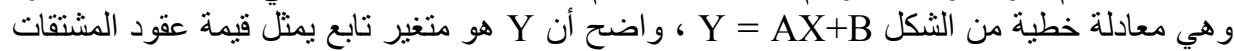

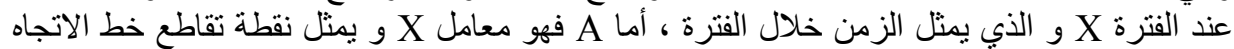

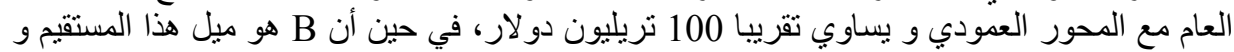

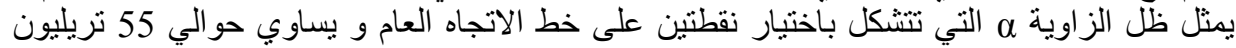
دو لار ، و بالتالي تصبح المعادلة كما يلي :

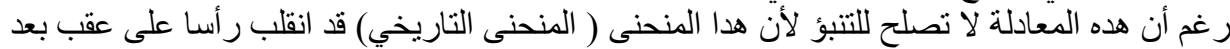

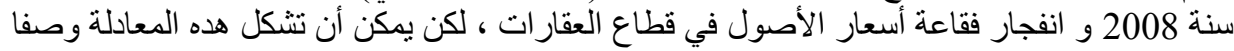

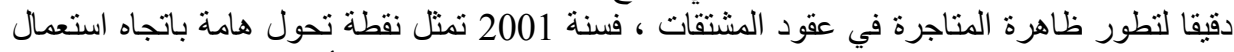

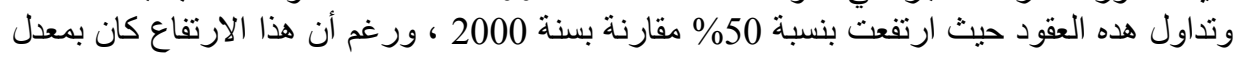

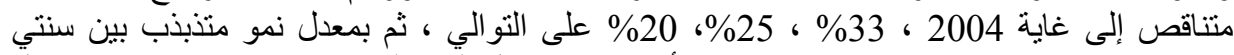

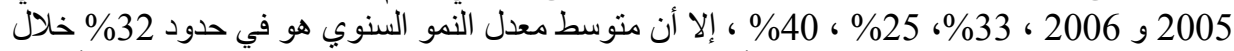

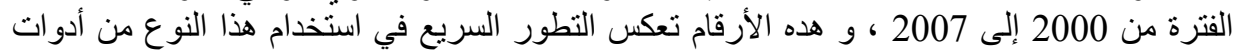

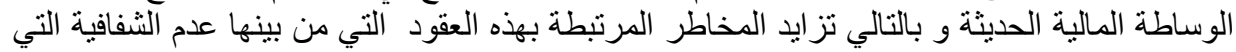

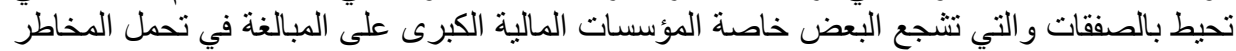

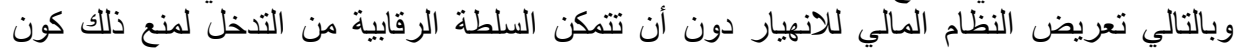

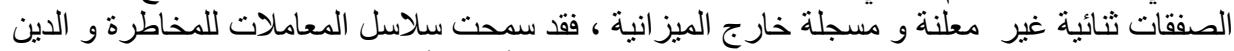

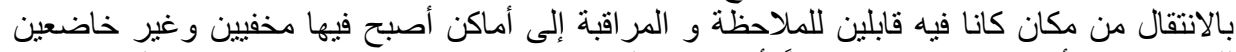

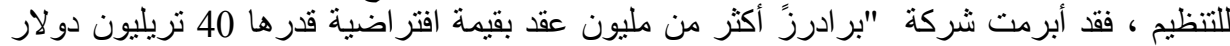

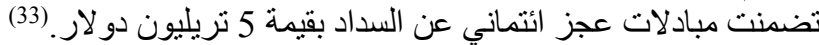

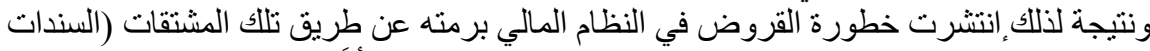

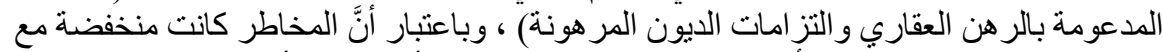

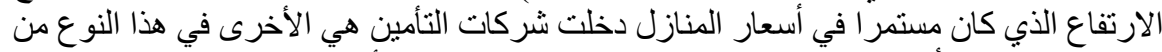

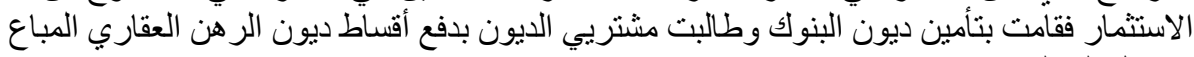

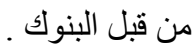


وبهذا قامت مشتقات سندات الرهن العقاري بربط عدد من الأطر اف ببعضهم في النظام المالي لا سيما

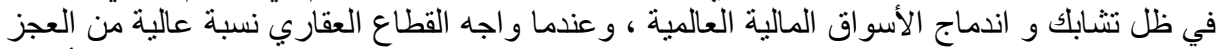

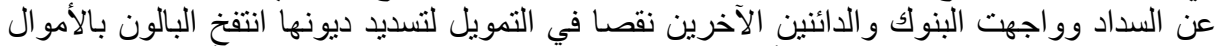

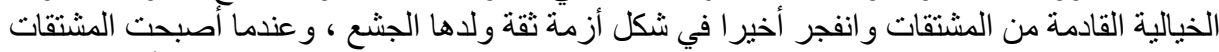

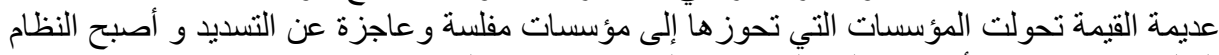

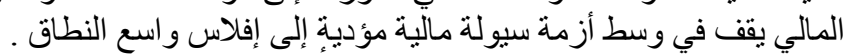

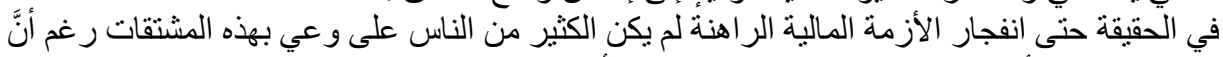

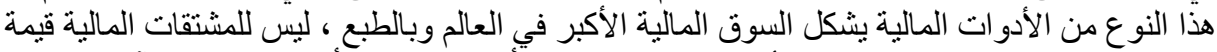

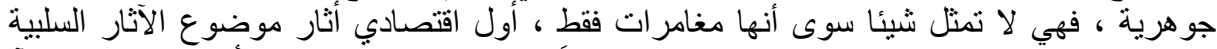

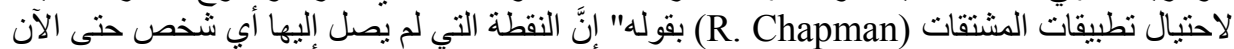

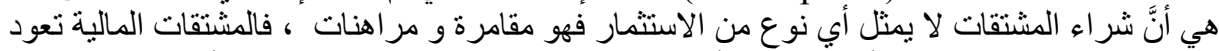

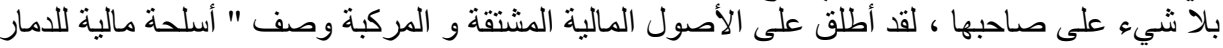

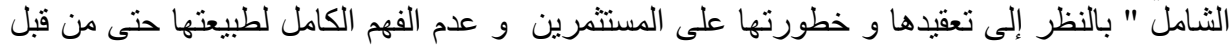

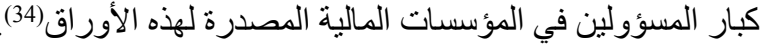

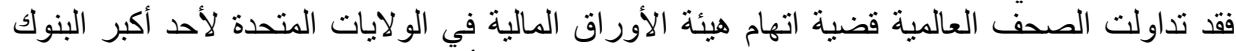

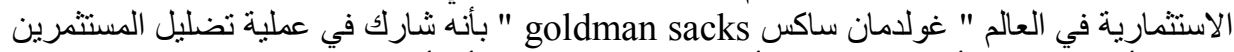

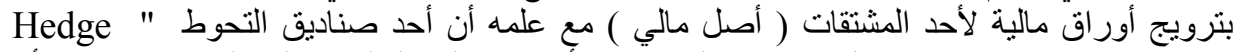
" funds

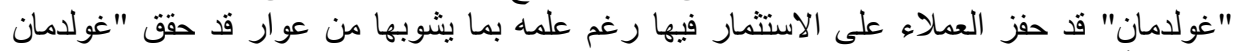

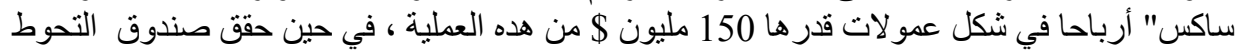

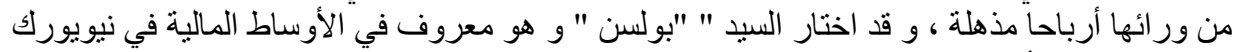

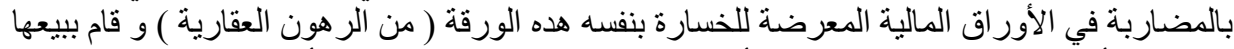

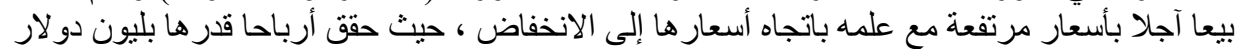

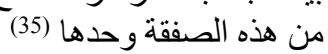

3-دور المشتقات المالية في اتساع الهوة بين الاقتصاد الحقيقي و الاقتصاد المالي

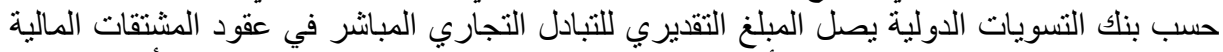

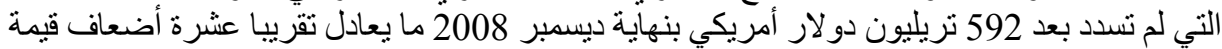

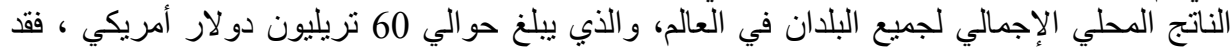

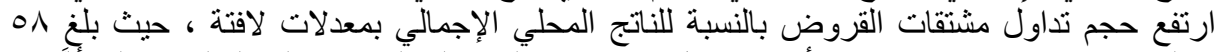

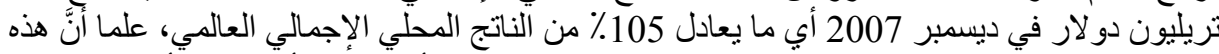

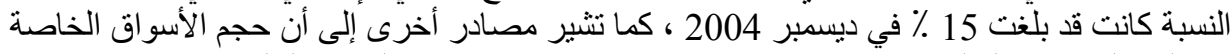

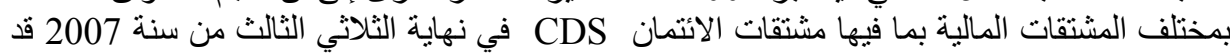
بلغ ما يعادل 681.000 مليار دو لار أمريكي. لقد نمت هده الأسواق بوتيرة سريعة جعلت حجم التداول في الأسواق المالية يفوق بعدة مرات التئ حجم

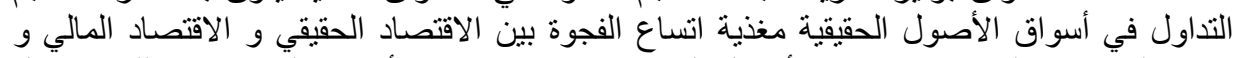

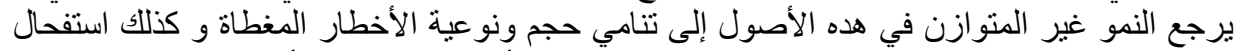

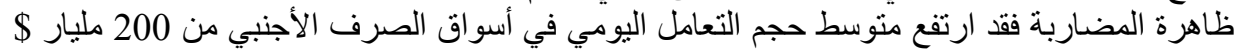

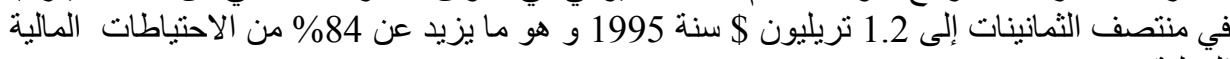
الدولية لكن بالمقابل أصبح هدا التطور يشكل تهديدا فعليا لاستقر ار الأسواق المالية و النظام المالي بشكل عام ،

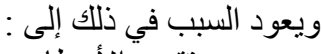
- - سوء تقدير الأخطار : 


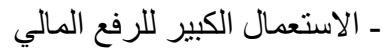

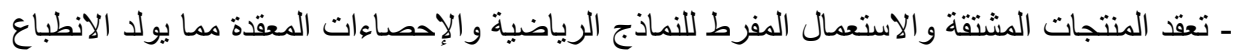

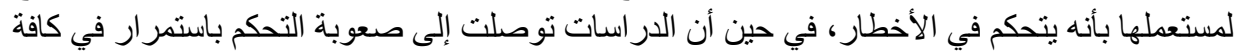

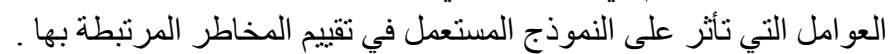

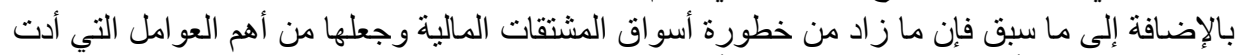

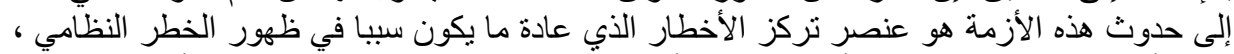

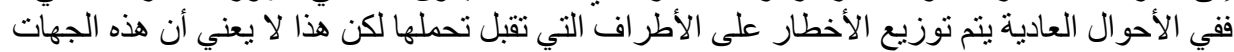

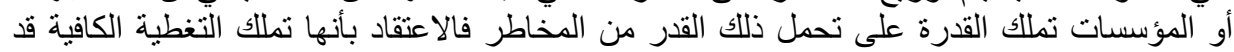

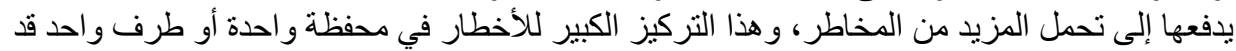

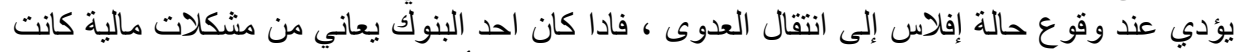

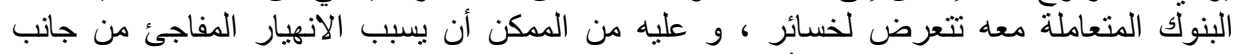

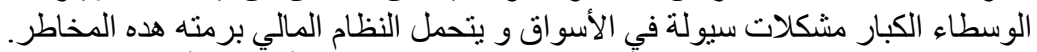

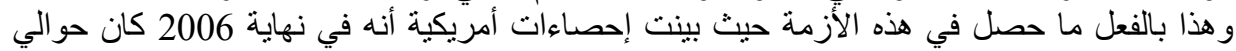

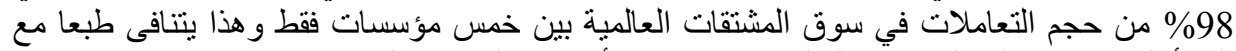

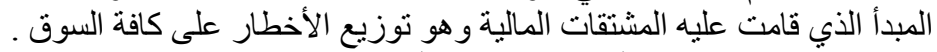

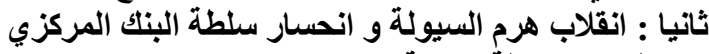

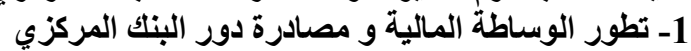

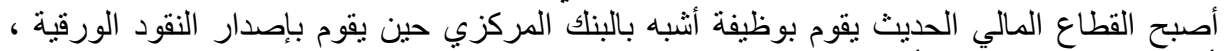

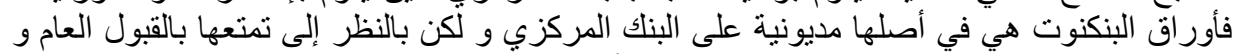

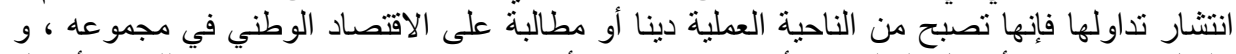

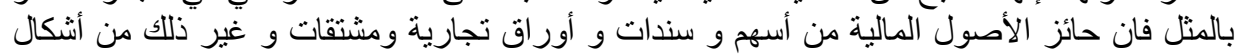

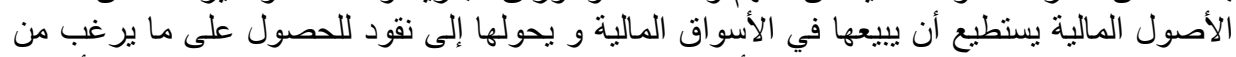

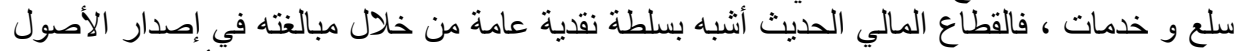

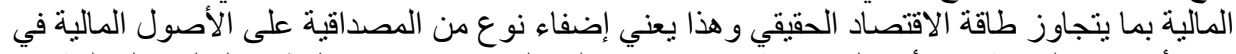

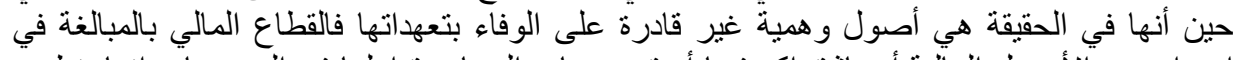

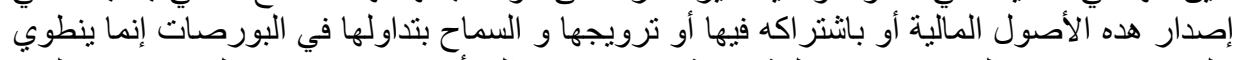

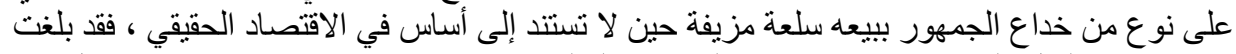

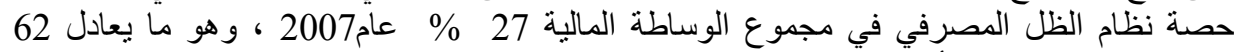

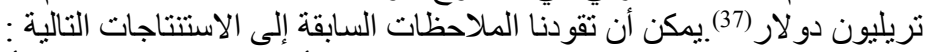

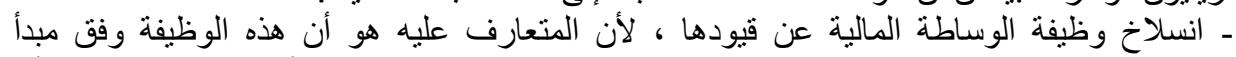

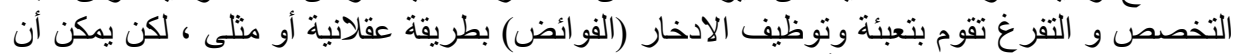

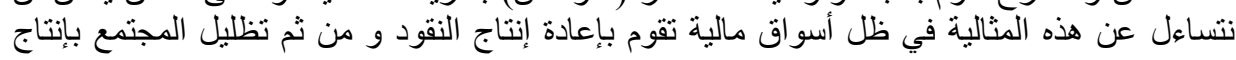

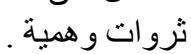

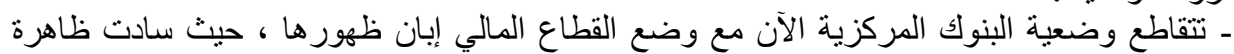

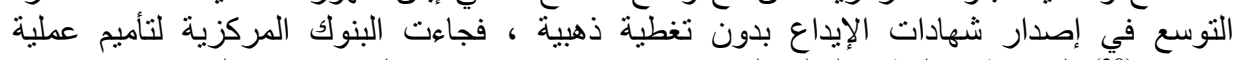

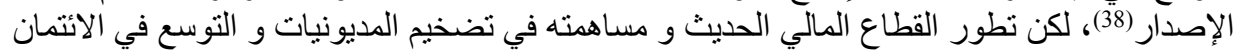

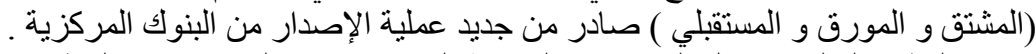

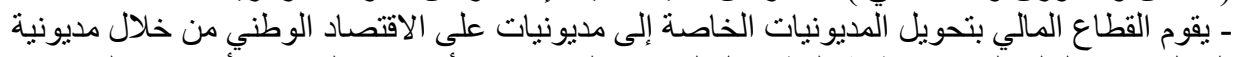

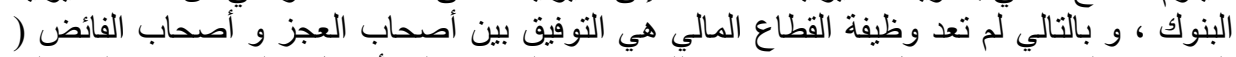

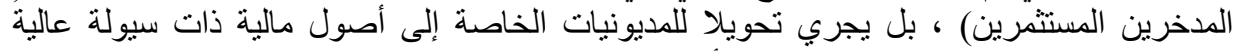

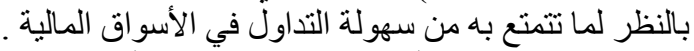
2- انقلاب هرم السيولة و دور البنوك المركزية النية 
لقد انعكس التطور الحاصل على مستوى الوساطة المالية و المرتبط بهيكل و أدوات الوساطة كما رأينا

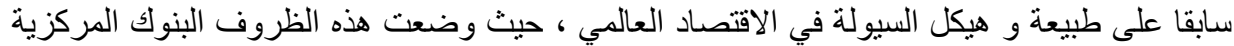

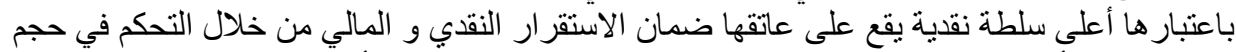

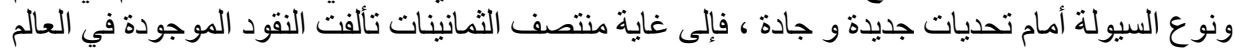

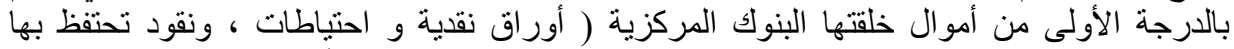

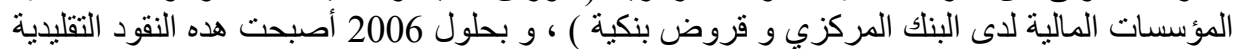

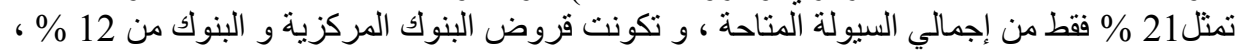

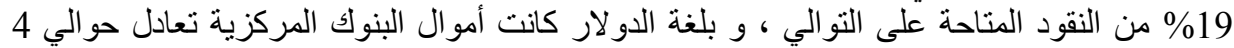

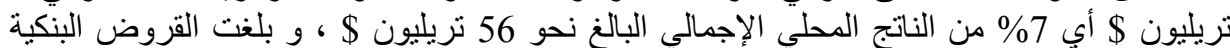
حو الي 42 تريليون \$ أي 75 \% من الَناتج المحلي الإجمالي العالمي. الثكل3 : هيكل السيولة العالمية 2006

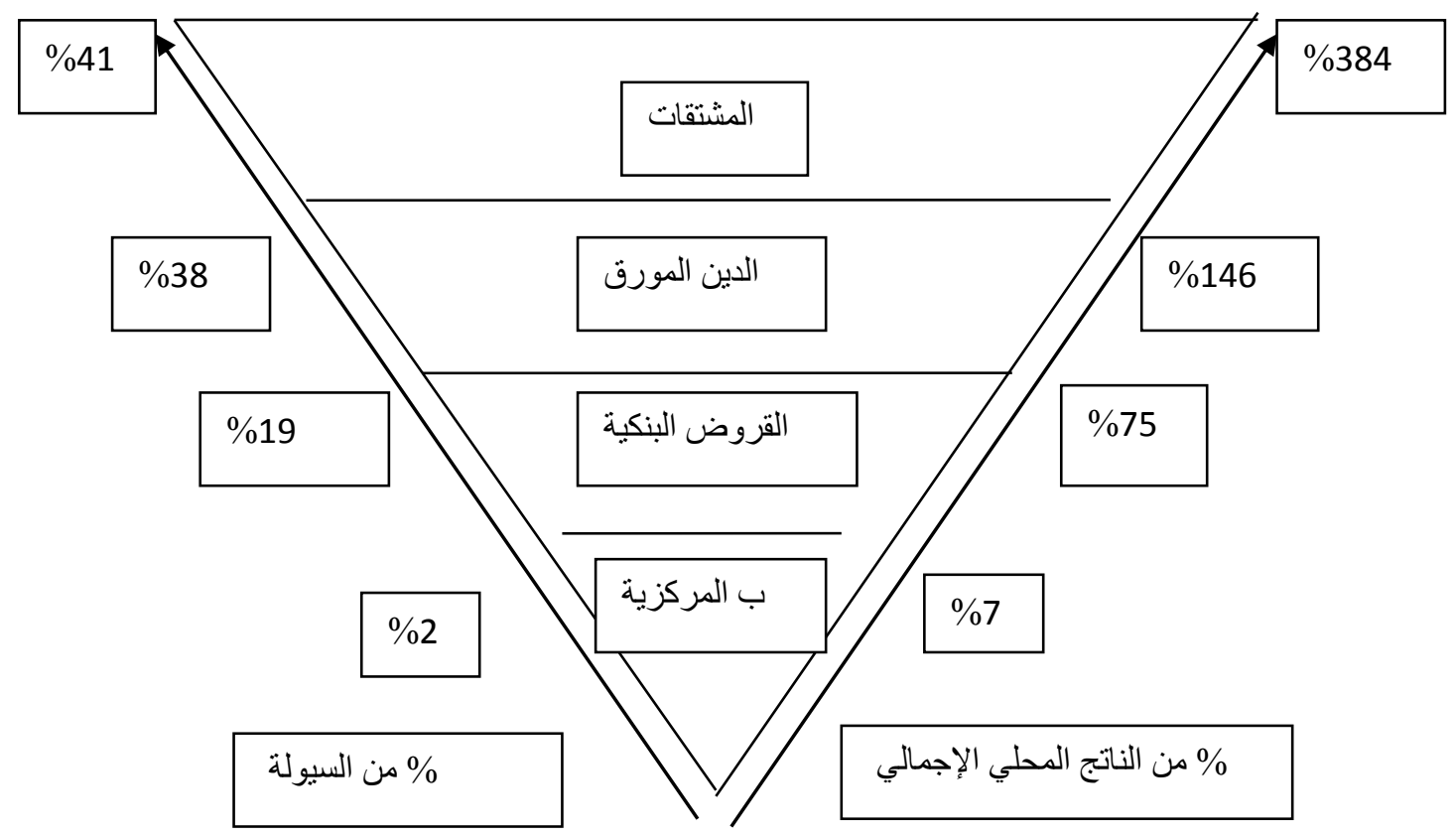

المصدر : ساتيا جيت داس ، مرجع سابق ، ص المبر 420

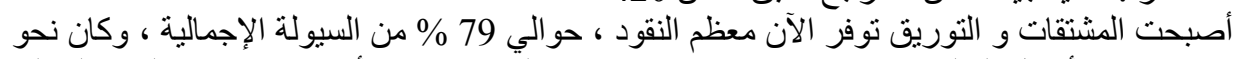

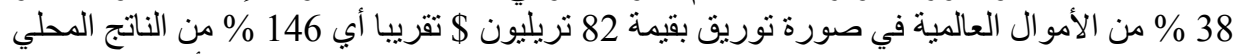

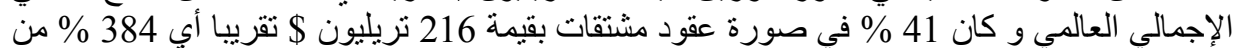

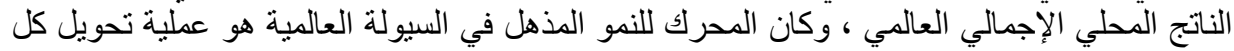

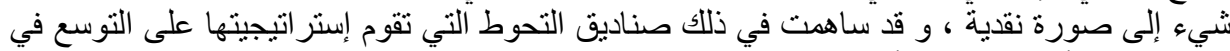

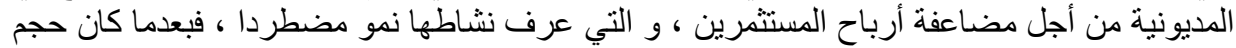


أصولها 39 مليار دو لار سنة 1990 ، أصبح 537 مليار دو لار سنة 2001 ، ليققز بعدها إلى تريليوني الصني

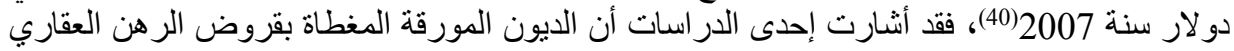

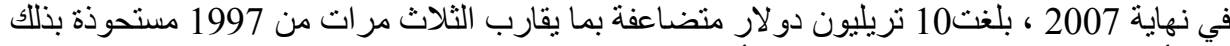

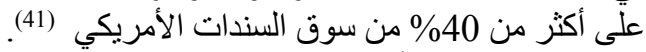

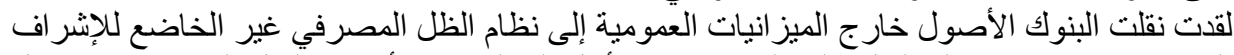

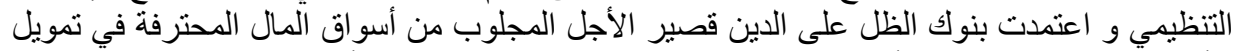

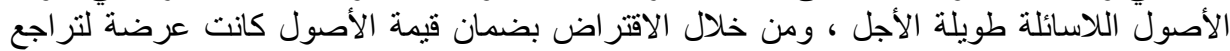

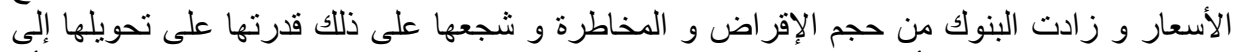

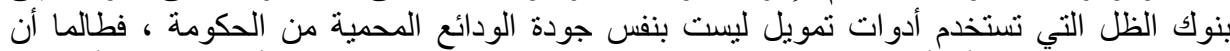

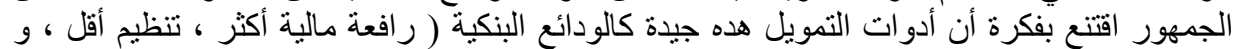

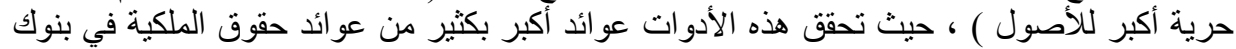

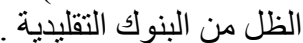

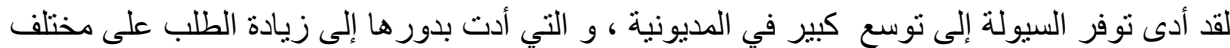

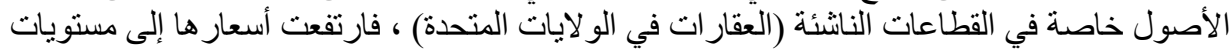

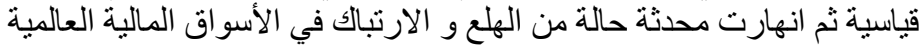

خلاصة:

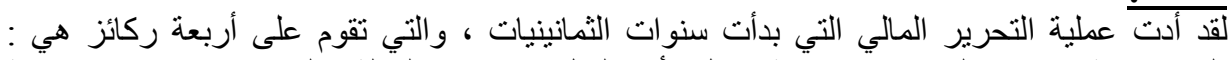

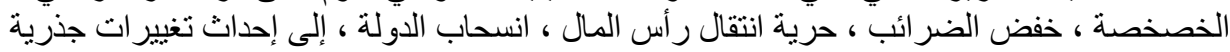

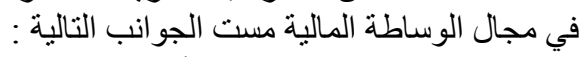

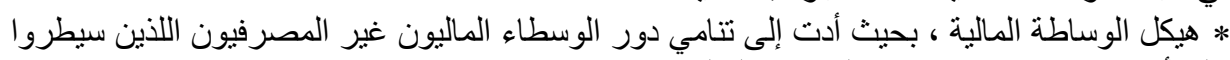

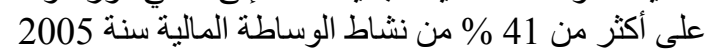

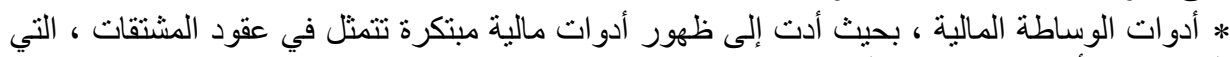

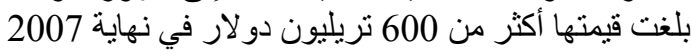

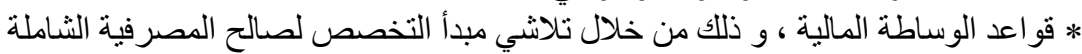

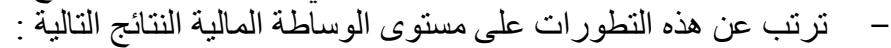
1- فقدان السلطات النقدية (البنوك المركزية ) السيطرة على الكئل الأسواق المالية و النقدية ، كون مؤسسات

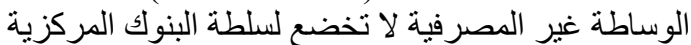
2- تتسم الأدوات المالية المبتكرة المتمثلة في عقود المشتقات بالغموض و والتركيب ، الذي يغذي عدم شفافية الأسواق المالية 3- كرست الأدوات المالية المبنكرة اتجاها جديدا للوساطة المالية الموغلة في استعمال أدوات الدين ،

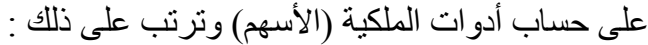

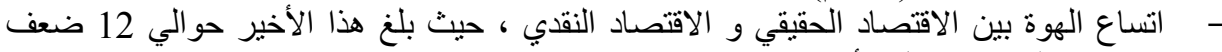

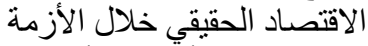

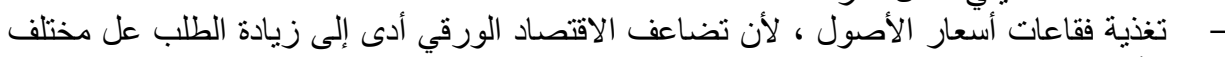

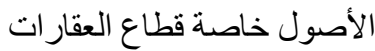

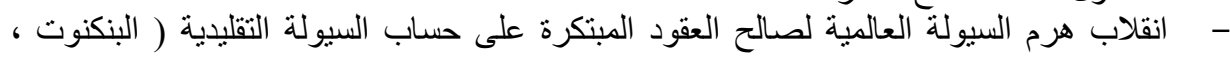

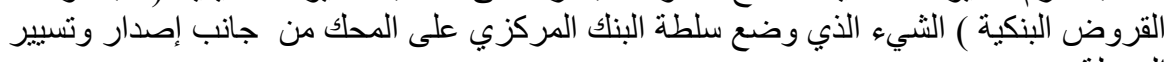
السيولة القرض 4- لقد عمقت الحقائق السابقة الثك في كفاءة الوساطة المالية القائمة على الدين(الفائدة) في تخصيص 
1- ضرورة وضع الإطار القانوني و التشريعي اللازم ، من أجل إخضاع مؤسسات الوساطة المالية غير المصرفية لسلطة البنكا المركزي الإني

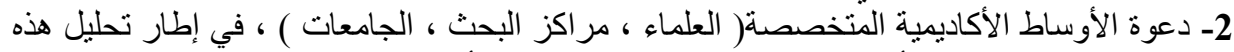
الظاهرة إلى تسليط الضوء أكثر على البدايات ( الفرضيات و والأسس) ، بدلا من التركيز على الطئ المظاهر

\section{و النتائج \\ قائمة المراجع}

1 ) عبد المنعم السيد علي ، نزار سعد الدين العيسى، النقود والمصارف و الأسواق المالية، دار

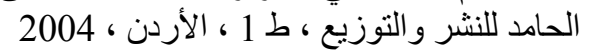

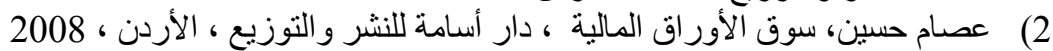

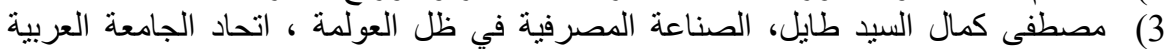
ل للنشر ، البلا لم يذكر ، 2009

4) محمود عبد العزيز ، مفهوم وظائف المصارف الثاملة ، اتحاد المصارف العربية ، بيروت لبنان ، 1994

5) حمد محمد غنيم، إدارة البنوك تقليدية الماضي و الكترونية المستقبل،المكتبة العصرية للنشر،

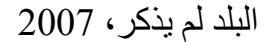

6) يوسف كمال محمد ، المصرفية الاسلامية الأزمة و المخرج ، دار النشر للجامعات ، ط3 ، مصر ، 1998

7) نزيه عبد المقصود مبروك ، صناديق الاستثمار بين الاقتصاد الإسلامي والاقتصاد الوضعي،

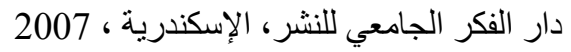

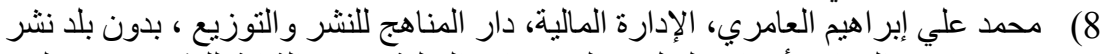

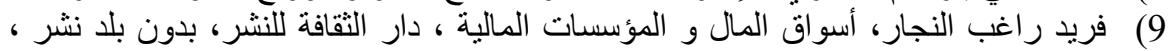
2009

10) محمد نجاة الله صديقي ، التأمين في الاقتصاد الإسلامي ، مركز النشر العلمي جامعة الملك

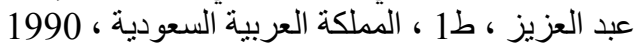
11) احمد صلاح عطية، محاسبة شركات التامين، الدار الجامعية للنشر ، مصردة ، التربة ، 2003

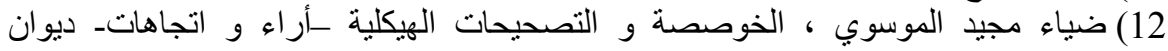

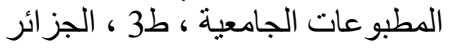

13) الطاهر لطرش ، الاقتصاد النقدي و البنكي ، ديوان المطبوعات الجرات الجعية ، ط1 ، الجزائر ، 2013

14) حمدي الصباحي ، مشكلات الاقتصاد الدولي المعاصر ، دار الحداثة للطباعة و النشر و التوزيع ، لبنان 15) هثام فوزي دباس العبادي، "الهندسة المالية وقدرتها بالتركيز على استراتيجيات الخيارات

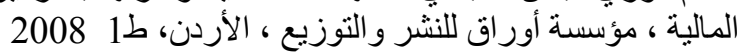

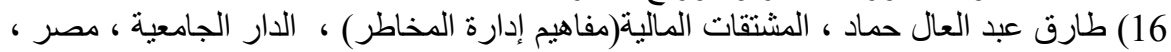
2003

17) طه بدوي ، عمليات بورصة الأوراق المالية الفورية والآجلة من الوجهة القانونية ، دار

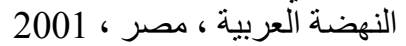

18) منير إبر اهيم هندي ، الفكر الحديث في إدارة المخاطر باستخدام التوريق و المثنقات المالية ج2 ، منشأة المعارف ، مندي ، مصر ، الفر ، 2003

19) طارق عبد العال حماد ، دليل المستثمر إلى بورصة الأوراق المالية ، الدار الجامعية ، الإسكندرية -مصر - 2002 
20) محمد صالح الحناوي ، و آخرون ، الاستثمار في الأوراق المالية ومشتقاتها ــ مدخل التحليل

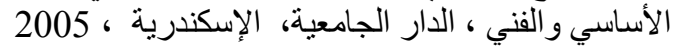

21) ساتبا جيت داس ، أسطورة المال - سادة العالم و إدمان المخاطر ـ ـ ، ترجمة علا أحمد صلاح

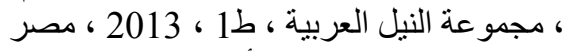

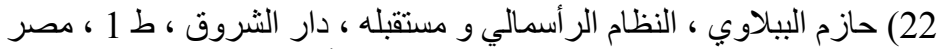

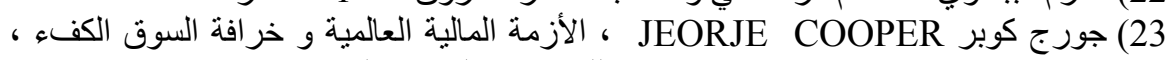

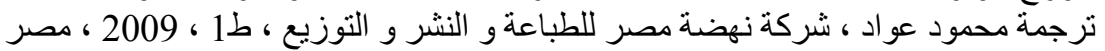

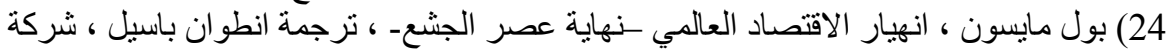

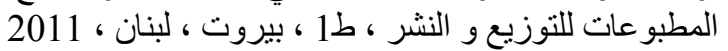

* المجلات و الملتقيات

$$
\begin{aligned}
& \text { 1) مجلة التمويل و التتمية ، صندوق النقد الدولي ، يونيو ، } 2013
\end{aligned}
$$

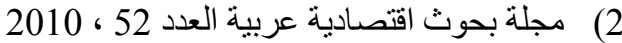

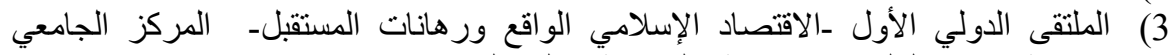

* العناوين الأكترونية

www.iasj.net/iasj? Func=fulltext\&aId $(1$

http://ar.wikipedia.org/wiki (2

http://uaesm.maktoob.com/vb/uae77312 (3

http://www.arabicactuary.com (4

www.bis.org/press/080609.pdf (5

http://seekingalpha.com/article/77282-a-commodity-hedge- (6

http://m.alomanaa.net/news/26 (7

الهوامش:

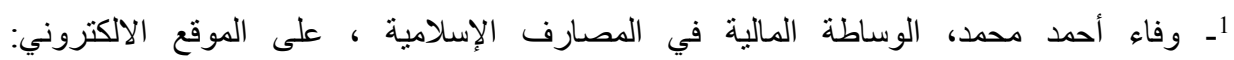
www.iasj.net/iasj? Func=fulltext\&aId

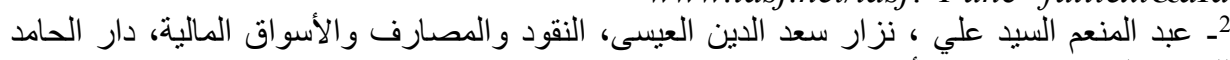

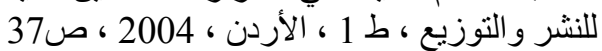

3-- د. عصام حسين، سوق الأوراق المالية ، دار أسامة للنشر و التوزيع ، الأردن ، 2008 ، ص ص

4 ـ ـ د. مصطفى كمال السيد طايل، الصناعة المصرفية في ظل العولمة ، اتحاد الجامعة العربية للنشر،

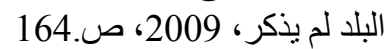

5ـ محمود عبد العزيز ، مفهوم وظائف المصارف الثشاملة ، اتحاد المصارف العربية ، بيروت لبنان ،

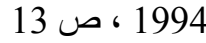

6 - حمد محمد غنيم، إدارة البنوك تقليدية الماضي و الكترونية المستقبل،الككتبة العصرية للنشر ، البلد لم

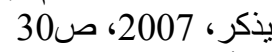

7ـ أنظر : - يوسف كمال محمد ، المصرفية الاسلامية الأزمة و المخرج ، دار النشر للجامعات ، ط3 ، 3208 ،

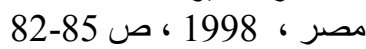

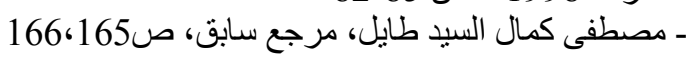


8 ـ دبراق محمد ، أداء صناديق الاستثمار المسئولة اجتماعيا وصناديق الاستثمار الإسلامية ، الملتقى الإنى الإني

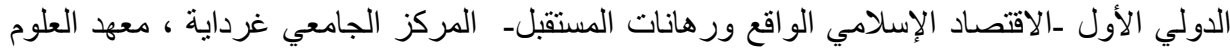

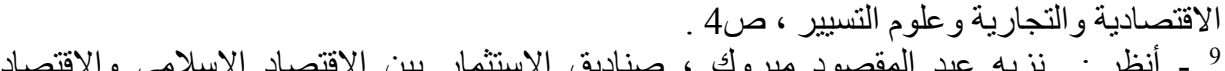

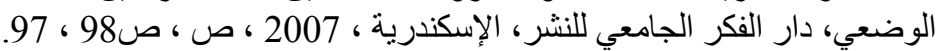

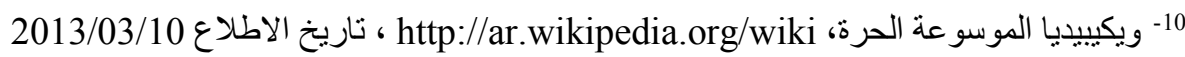

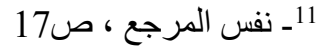

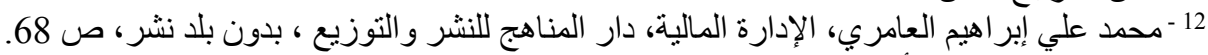

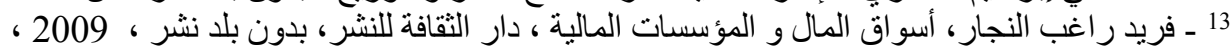

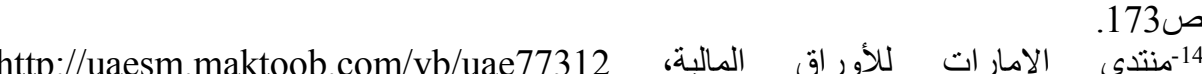
‘http://uaesm.maktoob.com/vb/uae77312 174 17:3013/04/25 14:30، 2013/04/10 ‘http://www.arabicactuary.com ${ }^{-15}$

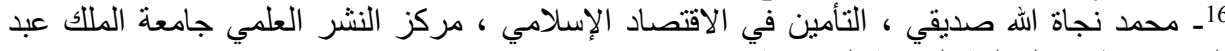

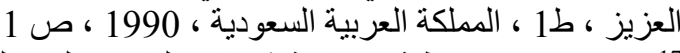

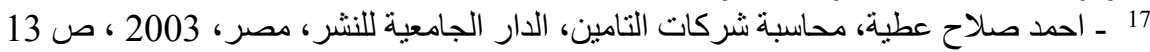

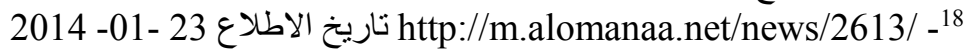

ـ ضياء مجيد الموسوي ، الخوصصة و و التصحيحات الهيكلية ـأراء و اتجاهاتـ ديوان المطبوعات

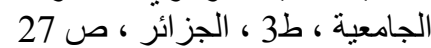

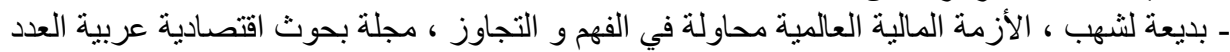

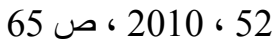

20 ـ الطاهر لطرش ، الاقتصاد النقدي و البنكي ، ديوان المطبوعات الجامعية ، ط1 ، الجزائر ، 2013

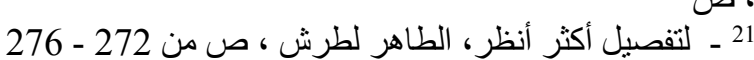

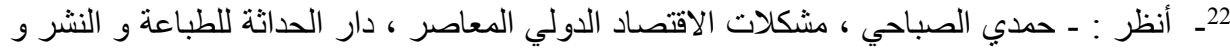

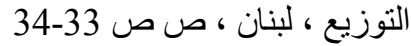

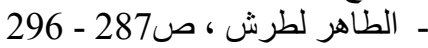

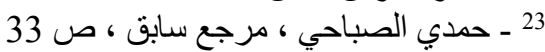

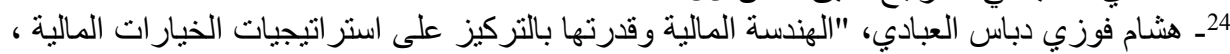

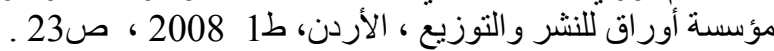

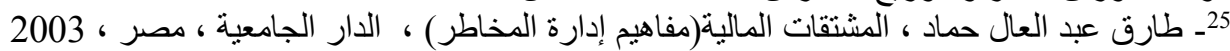

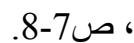

26ـ طه بدوي ، كمليات بورصة الأوراق المالية الفورية والآجلة من الوجهة القانونية ، دار النهضة

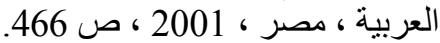

27ــ منير إبر اهيم هندي ، الفكر الحديث في إدارة المخاطر باستخدام التوريق و المشتقات المالية ج2 ،

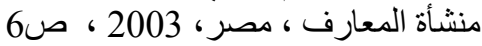

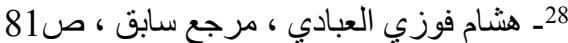

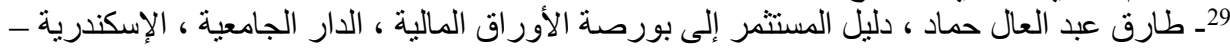

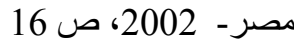




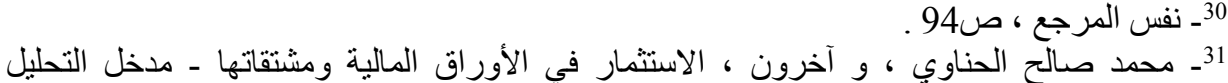

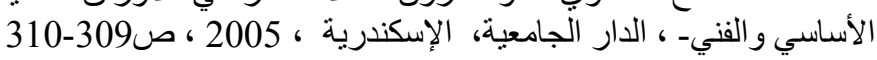

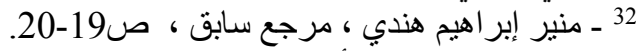

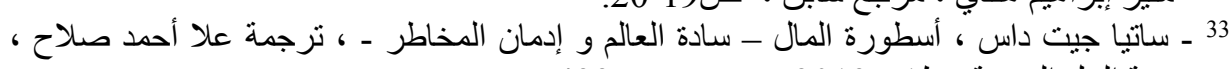

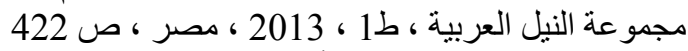

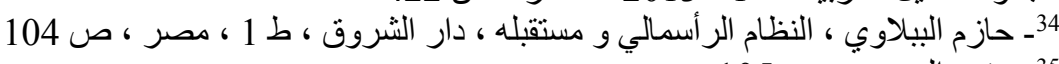
35 2013 - www.bis.org/press/p080609fr.pdf.- 36 37 ـ لورا كودريس ، ما هو نظام الظل المصرفي ، مجلة التمويل و التنمية ، صندوق النقد الدولي ،

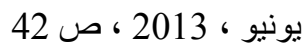

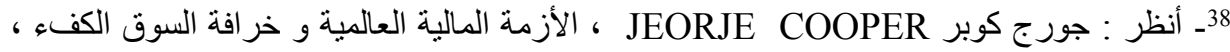
ترجمة محمود عو اد ، شركة نهضة مصر للطباعة و النشر و التوزيع ، ط1 ، 2009 ، مصر ، ص 44 $50-$ 39 ـ ساتيا جيت داس ، مرجع سابق ، ص الت 417

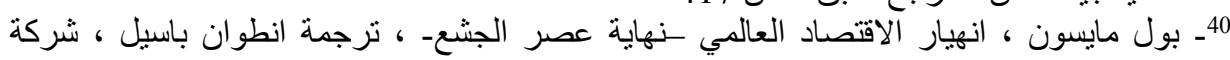

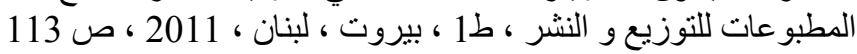
Patric Artus, la crise des supprimes, rapports du CAE,79(paris :la ${ }_{-41}^{41}$ documentation française 2008) $\mathrm{p}: 39$ 